\title{
The Opt-In Revolution? Contraception and the Gender Gap in Wages ${ }^{\dagger}$
}

\author{
Martha J. Bailey, \\ Department of Economics, University of Michigan, 611 Tappan Street, Ann Arbor, MI, 48109 \\ Brad Hershbein, and \\ Department of Economics, University of Michigan, 611 Tappan Street, Ann Arbor, MI, 48109
}

Amalia R. Miller

Department of Economics, University of Virginia, 237 McCormick Road, Charlottesville, VA 22904

Martha J. Bailey: baileymj@umich.edu; Brad Hershbein: bjhersh@umich.edu; Amalia R. Miller: armiller@virginia.edu

\begin{abstract}
Decades of research on the US gender gap in wages describes its correlates, but little is known about why women changed their career paths in the 1960s and 1970s. This paper explores the role of "the Pill" in altering women's human capital investments and its ultimate implications for lifecycle wages. Using state-by-birth-cohort variation in legal access, we show that younger access to the Pill conferred an 8 percent hourly wage premium by age 50. Our estimates imply that the Pill can account for 10 percent of the convergence of the gender gap in the 1980s and 30 percent in the 1990s.
\end{abstract}

During the 1980s, the long-standing US gender gap in pay narrowed rapidly. The median annual wage and salary earnings of full-time, full-year women workers rose from roughly 60 percent of men's earnings in 1979 to 69 percent a decade later. Not only was this decade a striking departure from the stability of women's relative pay during the 1970s, but the speed of women's convergence in the 1980s was also faster than during the 1990s and the 2000s.

The correlates of the narrowing of the gender gap in the 1980s are well documented. Expecting to remain in the labor force longer, women born in the 1950s (who came of age in the 1970s) narrowed the gender gap in college going and completion, professional degree attainment, and employment in nontraditionally female occupations (Goldin 2004, 2006). Increases in demand for skills that benefited women relative to men increased the returns to women's career investments in market skills (Blau and Kahn 1997; Welch 2000). Widening wage inequality among women also encouraged women to invest in market skills and led more able women to select into full-time employment (Mulligan and Rubinstein 2008). Each of these factors may have contributed to and resulted from the growth in women's work experience (O’Neill and Polachek 1993; Wellington 1993).

The root causes of these tremendous changes are less clear. Two important but elusive candidate explanations include the resurgence of the women's movement in the late 1960s and early 1970s and the new legal protections afforded to women under the 1964 Civil Rights Act (and later federal enforcement) that reduced overtly-discriminatory hiring and compensation practices. Recent literature suggests oral contraception, often called "the Pill,"

\footnotetext{
${ }^{\dagger}$ To comment on this article in the online discussion forum, or to view additional materials, visit the article page at http://dx.doi.org/ 10.1257/app.4.3.225.

Correspondence to: Amalia R. Miller, armiller@virginia.edu.
} 
as another important candidate. Its diffusion to younger, unmarried women improved their ability to time births, altered their expectations about childbearing during a period critical to career investment, and reduced the cost of increasing their early career investments. The timing of its diffusion during the 1960s and 1970s also fits well with the slow growth in women's wages during the 1970s (as younger women invested more in their human capital) and the rapid convergence in the gender gap during the 1980s (when these women enjoyed the returns on their human capital investments and accumulated labor-market experience). To quantify the importance of the Pill, Goldin and Katz (2002) use state-by-birth-cohort changes that reduced the age of consent from 21 to 18 and, thereby, also reduced the age of legal access to prescription birth control. Subsequent literature links this "early access to the Pill" to delays in marriage (among college goers) and motherhood, changes in selection into motherhood, increased educational attainment, labor-force participation, and (among college goers) occupational upgrading (Goldin and Katz 2002; Bailey 2006; Guldi 2008; Hock 2008; Ananat and Hungerman 2012).

This article examines the role of the Pill in altering women's life-cycle wages and its ultimate implications for convergence in the gender gap during the 1980s and 1990s. Although previous work implies that the Pill benefitted individual women's careers, changes in the composition of working women and increased labor supply mean that its effect on aggregate women's wages need not be large or even positive. Following earlier work, our empirical strategy leverages state-by-birth-cohort changes in laws reducing the age of consent for medical care and access to prescription birth control for unmarried women under age 21 . We extend the literature by providing new evidence relating to this empirical strategy's identifying assumptions. Using the 1970 National Fertility Study (NFS), we show that early access laws doubled Pill use among women between the ages of 18 and 20precisely the ages affected by access laws - but not beyond age 21 , when the laws did not bind. In addition, we test the excludability of Pill access laws (i.e., the assumption that early legal access to the Pill was conditionally, randomly assigned) using the National Longitudinal Survey of Young Women (NLS-YW). Among 18 family background characteristics that should not have been affected by these legal changes, early access to the Pill is correlated with only one at the 10 percent level—no more than would be expected by chance.

Using longitudinal wage information from the NLS-YW, our main results show that early access to the Pill lowered women's wages in their early twenties (corresponding to the 1970s) but raised their wages in their thirties and forties (corresponding to the 1980s and 1990s). By their late forties, women with early access to the Pill earned a statistically significant hourly premium of 8 percent-enough to account for between one-third and half of the total hourly wage gains for these cohorts over their peers born a decade earlier.

Consistent with the well-known relationship between women's wage growth and cumulative labor force experience, our decomposition indicates that almost two-thirds of the Pillinduced wage premium at the mean is explained through its effect on women's labor force experience. Another third of the premium is due to changes in educational attainment and occupational choice.

The NLS-YW also sheds light on the mechanisms for these effects. Stratifying our sample by measures of high school "IQ score" reveals that the flexibility conferred by the Pill had no measurable impact on the education or experience of lower IQ women. Both middle and higher IQ women, however, raised their educational attainment in their twenties and, in their thirties, acquired more labor-market experience and increased their representation in nontraditionally female occupations. Interestingly, the Pill's larger effects on work experience accrued to women in the middle of the IQ distribution with some college as did its effects on life-cycle wages. Thus, the rapid narrowing of the gender gap during the 1980s 
reflected, in part, a Pill-induced revolution in middle-ability women planning for and opting into paid work.

\section{The Revolution in Women's Work}

Aggregate statistics documenting women's wages from the 1950s and 1960s only hint at the tremendous changes in women's earning capacity. Goldin (1990, table 3.1) shows that women's real wages fell relative to men's from the 1950s to the 1960s. From the 1960s through the mid-1970s, the gap in pay remained constant at roughly 60 percent (Blau, Ferber, and Winkler 2010, figure 51). Beginning in the 1980s, the gender gap in wages narrowed substantially. Although this narrowing has continued to the present, its pace has slowed since the mid-1990s. To provide context for our cohort-age-based investigation, this section uses the 1964 to 2009 March Current Population Surveys (CPS) to describe by age and cohort the changes in women's wages and labor force outcomes, what Goldin (2006) dubbed the "quiet revolution." 1 We also present statistics relative to men to underscore the convergence in outcomes.

Figure 1 shows the evolution of mean annual wage and salary earnings in 2000 dollars (PCE deflator) for seven different birth cohorts of women relative to men-a measure of the agespecific gender gap for the following cohorts: those born from 1922 to 1927 (called mid-1920s), 1928 to 1932 (early 1930s), 1933 to 1937 (mid-1930s), 1938 to 1942 (early 1940s), 1943 to 1946 (mid-1940s), 1947 to 1950 (late 1940s), and 1951 to 1954 (early 1950 s). ${ }^{2}$ For cohorts born before the 1940 s, the relative wage series have similar age profiles. Beginning with cohorts born in the early 1940s, the gender gap increases less rapidly (i.e., the pay of women relative to men falls less rapidly) in women's twenties and rebounds more quickly after age 30. For 34-year-olds, annual incomes increased from 39 percent of similarly aged men for the 1938 to 1942 cohort to 55 percent for cohorts born less than a decade later.

Large changes in relative wage and salary earnings followed dramatic relative increases in women's pre-market and post-entry career investments. Goldin, Katz, and Kuziemko (2006) show that the share of women (relative to men) attending and completing college accelerated for cohorts born after the mid-1930s. Labor-force participation during the childbearing years grew rapidly as well. At the extensive margin, participation of 30-year-old women born in the mid-1940s increased by 16 percentage points (from a base of 39 percent) over cohorts born a decade earlier. For women born in the early 1950s, this statistic increased another 14 percentage points. ${ }^{3}$ Because the labor-force participation of men was stable over this period, these increases imply a narrowing in the cohort-based gender gap in participation, shown as a flattening of the relative labor force participation series plotted in Figure 2, panel A. Women's greater labor force participation also translated into considerably more work experience (cf. O'Neill and Polachek 1993; Wellington 1993). In the NLS-YW, we calculate that women born in the early 1950s worked 3,000 more hours between ages 24 and 40 than did women born in the mid-1940s — an increase of 1.5 full-time, 50-week years. ${ }^{4}$

\footnotetext{
${ }^{1}$ We use CPS rather than the NLS, because the CPS contain information on older cohorts and their larger sample sizes make our series less noisy. Data from the NLS-YW augment this discussion when informative.

${ }^{2}$ This divides the cohorts of the National Longitudinal Surveys of Mature and Young Women into roughly equal-sized groups. Wage and salary earnings in Figure 1 exclude farm, business, or self-employment income. Our sample excludes those who report zero earnings, but Figure 1 makes no further sample restrictions.

${ }^{3}$ Statistics for women alone are computed using the March CPS, but only statistics relative to men are presented for brevity.

${ }^{4}$ We cannot compare these estimates with cohorts born earlier than the mid-1940s, as the Mature Women were first interviewed when they were between the ages of 30 and 45 . Therefore, we are missing information on these older cohorts' labor force participation at younger ages. For construction of these experience measures, see online Appendix A.
} 
Changes in the nature of women's work for pay, along with their experience, also coincide with the narrowing of the cohort-based gender gap. The fraction of women working in professional or managerial jobs in their mid-thirties was roughly twice as high for cohorts born in the mid-1940s as for cohorts born a decade earlier. Figure 2, panel B shows that, after accounting for the increase in the share of men working in professional and managerial jobs, women's representation in these fields at age 30 increased by 25 percentage points between the cohorts born in the early and late 1940s and another 24 percentage points for cohorts born in the early 1950 s.

Although the remarkable, late-twentieth-century transformation in women's careers is well known, its catalysts are less well understood. Women may have been pulled into the labor force by changes in demand reflecting increasing enforcement of anti-discrimination legislation or skill- (and gender-) biased technological change (Welch 2000; Black and Juhn 2000; Weinberg 2000; Black and Spitz-Oener 2010). At the same time, rapidly changing ideas about women's work and roles in the workplace (Fernandez, Fogli, and Olivetti 2004; Fernandez and Fogli 2009; and Fortin 2009), shifts in divorce rates (Stevenson and Wolfers 2007), and the availability of better colleges and better education at the same colleges (Goldin and Katz 2010) may have increased the supply of women's skills to the market. The next sections describe the potential importance of the Pill for young women's decisions and wages and outline our empirical strategy for quantifying its role within the broader social and economic changes of the last 40 years.

\section{Was this an Opt-In Revolution? The Expected Effects of Changes in Pill Access on Women's Lifecycle Wages}

The diffusion of oral contraception, first released for the regulation of menses in 1957 and approved by the US Food and Drug Administration as a contraceptive in 1960, had an important impact on younger women's ability to time births and plan future childbearing. Women born in the early 1940s (who would be young adults in the early 1960s) would have been the first with access to the Pill in late adolescence when they made decisions about family formation, childbearing, and career investments. They would have also been the first to gain autonomy in deciding to use contraception (rather than sharing it with their partners), the first to be able to make decisions about contraception at a time separate from intercourse, and the first to benefit from the reliability and expectation of birth predictability the Pill conferred over years crucial to their human capital investment. Changes in expectations even affected women who, without the Pill, would not have married or had a child before age 22, as these women did not know this would be the case at age 18 .

The difficulty of parsing the Pill's effect on women's wages relates to the timing of its appearance. By cause or coincidence, its diffusion coincided with important changes in norms and ideas about women's work and the end of the baby boom. Following Goldin and Katz (2002) and Bailey (2006), our empirical strategy makes use of state-level variation within birth cohorts in "early legal access to the Pill" (ELA), which allowed younger women to consent for medical care. As described in Bailey (2006), most legal changes were due either to judicial expansions in the rights of legal minors or to legislative changes that lowered the age of majority to 18. The timing of changes in ELA differed considerably across states (the earliest change was in 1960 and the latest in 1976), but the common feature of these laws is that they gave physicians latitude to prescribe oral contraception to unmarried women under 21 without consulting parents (Paul, Pilpel, and Wechsler 1974, 1976). State-by-birth cohort variation in ELA, therefore, facilitates comparisons of laborforce outcomes for women who gained legal access to the Pill earlier (typically at their eighteenth birthdays) to those who gained access at 21 . 
This three-year difference in access to the Pill during a formative life stage potentially affected a host of decisions. Having early access to the Pill, for instance, directly reduced the cost of delaying childbearing and marriage to enter or stay in college. ${ }^{5}$ Even among women who did not attend college, better fertility control reduced the cost of remaining at a job long enough to obtain a promotion or additional training. In addition, early access to the Pill may have altered the expected returns to early human capital investments. All else equal, the expected lifetime returns to human capital investments would increase if women anticipated lower costs of completing them. In short, earlier access to the Pill should have both reduced the costs of and increased the expected returns to early career investments-predictions consistent with the empirical literature's findings. Hock (2008) and Ananat and Hungerman (2012) show Pill access affected college enrollment and education. Bailey (2006) shows that it increased women's labor-force attachment, and Goldin and Katz (2002) find that it increased college women's representation in nontraditionally female professions.

This framework suggests three (potentially reinforcing) mechanisms linking ELA to steeper wage and salary earnings profiles. First, ELA may have increased school enrollment and participation in training programs, which should lower wage earnings at younger ages, and increase them following school exit. We call this channel the "formal human capital investment mechanism." Second, ELA may have increased labor-force participation, which should enable women to accumulate more labor-market experience and job- or firm-specific human capital and, thus, have more rapid wage growth. We call this mechanism the "experience mechanism." Third, women with ELA may have shared the costs of gaining onthe-job human capital by accepting lower initial wages but then enjoying more rapid wage growth with tenure. We call this channel the "on-the-job-investment mechanism."

There are two off-setting forces as well. Because ELA could increase labor-force participation for large numbers of women (and, thus, reduce the capital-to-labor-ratio), its effect on any one woman may be larger than its effect on an entire birth cohort, the parameter recovered in the analysis. As shown in the online Theory Appendix, the magnitude of these supply-side effects depends (among other things) on the degree of substitutability of male and female labor in production. The closer substitutes men and women are in production, the smaller the labor-supply effect and the more likely the overall effect of ELA on wages will be positive (due to its effect on human capital accumulation). Our estimates include this labor-supply channel, so our estimates will tend to understate the effect of the Pill on an individual woman's wages, especially in the shorter run (at younger ages), before firms adjust their capital stock.

Changes in selection, while endogenous, also complicate the analysis. Because wages are only observed for labor market participants, the observed impact of ELA on women's wage growth will be larger than the effect on the average woman if the Pill differentially affects human capital investments and labor supply of higher ability women. If, for instance, early access to the Pill causes higher ability women to continue in their education and makes them less likely to work in their early twenties, then the ELA-induced growth in wages will reflect both the returns to these greater investments and changes in the composition of working women to favor those of higher ability. Our analysis explores these compositional effects explicitly by breaking our sample into three IQ tertiles (based upon a composite developed

\footnotetext{
${ }^{5}$ A lower risk of childbearing at ages 18 to 19 may have also affected when and whom women married, which could have an independent effect on their careers (Chiappori and Oreffice 2008). Staying in college longer could allow marriage to a more educated man and, therefore, increase a woman's nonwage income and reduce her labor-supply (Ge 2011). On the other hand, staying in college longer should increase a woman's own earnings and, therefore, increase her options outside of marriage. If this leads to greater divorce, women would have lower nonwage incomes and, therefore, tend to work more at older ages (and younger ages, to the extent that women are risk averse and forward looking). For both reasons, marriage delay may improve women's career outcomes independently of fertility delay (Loughran and Zissimopolous 2009; Miller 2011).
} 
from high school aptitude tests) and examining the effects of ELA for women within each of these tertiles.

\section{Data and Empirical Strategy for Identifying the Impact of the Pill on Wages}

Our analysis uses the rich, longitudinal data of the NLS-YW, which contains information beginning in 1968 for 5,159 women, ages 14 to 24, with 21 subsequent interviews. Crucial is that the NLS-YW sampled women born from 1943 to 1954, cohorts that varied in their early legal access to the Pill. Although this dataset is smaller than those used in earlier studies, the restricted version contains information on the legal state of residence for the respondents at age 21 . We use residence at age 21 (which should be reported as parents' residence for unmarried, college women) to infer treatment status with considerably less error than previous studies. ${ }^{6}$

The NLS-YW confers several additional advantages. It contains a rich set of pretreatment outcomes for testing the validity of our empirical strategy and also facilitates an analysis of heterogeneity in the impact of the Pill by socioeconomic status and high school IQ of the respondent, which allows us to understand the ways in which the Pill influenced the selection of women into paid work. ${ }^{7}$ Finally, the NLS-YW provides information on women's wage earnings in every survey year as well as their career investments including educational attainment, job training and certification, and labor-force participation (weeks and hours). Repeated reports of women's labor-force participation allows us to construct measures of their cumulative labor-force experience, and link the Pill to this important correlate of women's wage gains.

\section{A. Empirical Specification}

Our empirical strategy follows the previous literature with several modifications. We estimate the following linear regression models for continuous dependent variables,

$$
Y_{i a c s}=\sum_{g} \beta_{g} E L A_{c S} D_{g(a)}+\sum_{g} \lambda_{g} D_{g(a)}+\sum_{s} \lambda_{s} D_{s}+\sum_{c} \lambda_{c} D_{c}+\eta_{i a c s}
$$

where $Y$ is the outcome of interest for individual $i$, at age $a$, who was born in year $c=1943$, $1944, \ldots, 1953$ (also referred to as "birth cohort"), and residing in state $s=1,2, \ldots, 51$ at age 21. Fixed effects for state of residence, $\sum_{s=2}^{51} \lambda_{s} D_{s}$ where $D_{s}=1$ if $i$ resided in state $s$ at age 21, and single year-of-birth cohorts, $\sum_{c=1944}^{1953} \lambda_{c} D_{c}$, where $D_{c}=1$ if $i$ was born in year $c$, are included in all specifications. The dummy variables $D_{g(a)}$ are set to 1 if the respondent's age fell into the five-year age group, $g(14-19,20-24, \ldots$, or 45-49). Standard errors for all models are robust to heteroskedasticity and clustered at the state level. ${ }^{8}$

Early legal access to the pill, $E L A_{c s}$, is equal to one if a woman born in year $c$ would have had access to oral contraception before age 21 in her state of residence at age 21 , and

\footnotetext{
${ }^{6}$ Restricting the sample to those with valid date of birth (cohort) and state of residence information reduces the sample to 4,354. Both Goldin and Katz (2002) and Bailey (2006) use repeated cross-sections that contain no information on an individual's state of residence at ages 18 to 21. As a result, Goldin and Katz (2002) and Bailey (2006) infer ELA based upon the reported birth state or state of residence at the time of the survey, respectively.

${ }_{8}^{7}$ Online Appendix A describes the survey questions and coding of each variable.

${ }^{8}$ For dichotomous dependent variables, we estimate probits and report average partial effects (APEs). The standard errors are calculated using a nonparametric bootstrap method with states as clusters (1,000 repetitions).
} 
interactions of $E L A$ with the age-group dummy variables allow its effect to vary across the lifecycle. Therefore, the key parameters of interest, the $\beta_{g}$ terms, measure differences in the outcome of interest in age group $g$ between women with and without early legal access to the Pill. $\beta_{g}$ will understate the impact of early Pill access if local compliance and enforcement were imperfect (young women drove across state lines to obtain the Pill or doctors prescribed it to underage women).

The main modification to Bailey (2006) is that we rely upon a revised legal coding (see online Appendix B). This updated legal coding reduces measurement error in ELA and allows the estimation of more precise effects over the lifecycle. Because these laws are not used elsewhere in the literature, the following section establishes their relationship with Pill use and subjects them to validity checks using detailed information on pretreatment characteristics.

\section{B. Validity of Using ELA to Identify the Impact of the Pill}

One important assumption required to obtain consistent estimates of $\beta_{g}$ is that ELA is uncorrelated with the error term after conditioning on state, age-group, and birth-cohort fixed effects, or $\operatorname{cov}(E L A, \varepsilon \mid \mathbf{Z})=0$, where $\mathbf{Z}$ captures the fixed effects in equation (1).

One reason that $\operatorname{cov}(E L A, \varepsilon \mid \mathbf{Z})$ may not be zero is that ELA may not be conditionally, randomly assigned at baseline. That is, a systematic correlation between omitted characteristics and ELA could drive the relationship between ELA and outcomes. Because the NLS-YW contain rich information on respondents' backgrounds at age 14 before treatment with ELA, we test this possibility using the following specification,

$$
X_{i c s}=\gamma E L A_{c s}+\sum_{s} \lambda_{s} D_{s}+\sum_{c} \lambda_{c} D_{c}+\varepsilon_{i c s}
$$

where $X$ is a pretreatment characteristic and other notation remains as previously described. Thus, $\gamma$ measures the residual correlation between $E L A$ and pretreatment characteristics that could indicate correlations with other, unobserved characteristics. (This approach is akin to testing for balance in observable characteristics in a controlled experiment.) Failure to reject $\gamma=0$ is consistent with conditional random assignment of early legal access to the Pill. Although the power of this test is limited by our small sample sizes, it provides a useful validity test of the empirical strategy.

Table 1 reports the results of this exercise for 18 pretreatment characteristics including a binary variable for whether the respondent's father was born in the United States; a binary variable for whether the respondent's father/mother worked for pay or held a professional job when she was 14 (four separate outcomes); an occupational prestige index for the father, conditional on working; a socioeconomic status index for the respondent's parents in 1968; a binary variable for whether the respondent resided on a farm or in a rural area at age 14; a binary variable for whether the respondent had access to magazines, newspapers, or a library card at age 14 (three separate outcomes); a binary variable for whether the respondent lived in a household with two parents at age 14; the number of siblings a respondent had; the highest grade completed by father/mother by 1968 (two separate outcomes); the number of years of schooling parents wanted the respondent to obtain when she was age 14; the atypicality of the respondent's mother's job (conditional upon mother working; negative numbers represent more atypical outcomes); and the respondent's IQ score in high school (see online Appendix A for details). Each column represents a separate, least-squares regression estimate of $\gamma .{ }^{9}$ Consistent with treating ELA as conditionally, randomly assigned, only one of the 18 estimates is statistically significant at the 10 percent level—no 
more than expected by chance. It is also reassuring that the pattern of correlations suggests no consistent relationship between ELA and the pretreatment characteristics. For instance, ELA is negatively associated with father's employment and with family socioeconomic status, but is positively associated with mother's education and professional employment.

Even if ELA is conditionally, randomly assigned, another reason that $\operatorname{cov}(E L A, \varepsilon \mid \mathbf{Z})$ may not be zero is that ELA is packaged with other policy changes. Although the history of these legal changes makes this unlikely, one concern is that cohorts with ELA were differentially treated with abortion access by chance-a treatment that could have a similar effect. Although data limitations mean that abortion access cannot be measured directly, our analysis accounts for this possibility by augmenting our equation (1) with a rich set of abortion controls:

$$
\begin{gathered}
Y_{\text {iacs }}=\sum_{g} \beta_{g} E L A_{c s} D_{g(a)}+\sum_{g} \lambda_{g} E A A_{c s} C 50_{c} D_{g(a)}+\sum_{g} \theta_{g} E L A_{c s} E A A_{c s} C 50_{c} D_{g(a)} \\
+\delta \ln D i s t_{s} C 50_{c}+\sum_{g} \lambda_{g} D_{g(a)}+\sum_{s} \lambda_{s} D_{s}+\sum_{c} \lambda_{c} D_{c}+\eta_{\text {iacs }}
\end{gathered}
$$

where $E A A$ represents "early access to abortion" and is equal to 1 if an individual resided (at age 21) in Alaska, California, the District of Columbia, Hawaii, New York, or Washington, states that legalized abortion in 1970. C50 is equal to 1 for birth cohorts born in 1950 or later, because the early legalization of abortion in 1970 could not have affected Pill use or fertility timing among 18- to 20-year-olds before 1970 (cohorts born before 1950). It is also important to note that any cohort-invariant, state-level differences in access to abortion will be captured in the state effects. The interaction of EAA and $C 50$ with agegroup dummies allows the differential evolution of outcomes for state-birth-cohort groups exposed to legal abortion in their state of residence before their twenty-first birthdays. Separate interactions of $E A A$ and $C 50$ with $E L A$ and age-group dummies allow early abortion access and early access to the Pill to be complements or substitutes. Finally, crossstate travel to obtain abortion is accounted for by inclusion of log distance to the nearest large city providing legal abortions to out-of-state residents (Buffalo, New York City, Los Angeles, San Francisco, or the District of Columbia), ln Dist $t_{s}$, for cohorts born in 1950 or later (cf. Joyce, Tan, and Zhang 2010). Therefore, the key parameters of interest, $\beta_{g}$, measure differences in outcomes in age group $g$, between women with and without ELA, for cohorts that did not have early access to abortion in their home state, after adjusting for cohort-level changes in cross-state travel for abortion. ${ }^{10}$

Finally, we test the sensitivity of our results in four alternative specifications of $\left(1^{\prime}\right)$ : one with linear, state-specific time trends; another with controls for Vietnam casualties; ${ }^{11}$ another using only a balanced sample of individuals (those missing information in any year or attriting are omitted); and another using state where the respondent attended high school to match to $E L A$ rather than state of residence at 21 years of age. ${ }^{12}$

\footnotetext{
${ }^{9}$ Linear probability models are used for binary outcomes to circumvent potential problems with disclosure. The results are robust to using negative binomials and probits where appropriate.

${ }^{10}$ Disclosure limitations from the Research Data Center prevent us from reporting effects for $E A A$ and the ELA-EAA interactions, although we can summarize these findings generally. We find that early abortion access does have independent effects on many (but not all) of the outcomes we examine. The coefficients on the interactions are consistent with the Pill and abortion acting as substitutes, which agrees with Ananat and Hungerman (2012), although the estimates are seldom statistically significant. The inclusion of these abortion controls has a negligible effect on the $E L A$ point estimates, as can be seen by comparing estimates here to those without abortion controls in online Appendix C.

${ }^{11}$ Using data from the National Archives on the Vietnam Conflict, the specification in equation $\left(1^{\prime}\right)$ is augmented with controls for state-level casualties. These controls include state-specific annual death rates lagged one, two, and three years; and cohort-specific, state-level death rates within two years of a woman's date of birth.

${ }_{12}$ Due to disclosure requirements on implicit sample sizes, we cannot include all of these controls and restrictions in one specification. More details on each specification can be found in online Appendix A.
} 


\section{The Relevance of Early Legal Access for Pill Use}

Testing the importance of ELA for women's use of the Pill is more difficult, because the NLS-YW contains no information on young women's contraceptive decisions. Goldin and Katz (2002) examined this question with a single cross-sectional dataset (1971 National Study of Young Women, NSYW 71) and found that a lower age of consent increased Pill use among 17- to 19-year-olds by 4 percentage points ( 40 percent), but it is unclear how this evidence bears upon this analysis. Goldin and Katz (2002) use a different legal coding, which means their estimates may not generalize for our analysis. In addition, their single cross-section of data in the NSYW 71 cannot be used to estimate the implicit first stage of this analysis, because state and cohort fixed effects cannot be included. Key for our investigation is that ELA increased Pill use at ages 18 to 20, after conditioning on year-ofbirth and state fixed effects.

The 1970 NFS, which asked ever-married women to recall Pill use over the decade of the 1960 s, allows us to examine this question directly for the subset of women who were ages 17 to 21 in the 1960s and married by 1970. Using a linear probability model, we estimate equation (2), where $X$ is a binary dependent variable equal to 1 if a respondent first used the birth control pill before age $a$, which we estimate separately for $a=18,19, \ldots, 22$. So that we observe each of the birth cohorts at each of these ages, the analysis restricts the sample to the birth cohorts of 1942 (age 18 in 1960) to 1948 (age 22 in 1970). Thus, estimates of $\gamma$ are based upon the subset of states that transition to ELA before 1970 (Georgia, Kentucky, Mississippi, Ohio, and Washington), which are different than the full set used in the remainder of the analysis.

Panel A of Table 2 uses these data to show that ELA increased Pill use at the appropriate ages. By chance, it appears that women in the five states that transitioned to ELA before 1968 were significantly less likely to use the Pill before age 18 . However, women with ELA were 17 percentage points more likely to use the Pill before age $19 .{ }^{13}$ Pill use before age 21 was 16 percentage points higher among women with ELA, a statistically significant 42 percent increase over the national mean. This difference falls to a statistically insignificant 5 percentage points at age 21 (before 22), when women without ELA could also obtain the Pill legally. ${ }^{14} \mathrm{~A}$ chi-squared test rejects at the 5 percent level $\left(\chi^{2}(4)=11.03\right)$ that the effects of ELA on Pill use before ages 19, 20, 21, and 22 are jointly equal to zero.

Panel B of Table 2 explores heterogeneity in this effect by the community size of the primary sampling unit. We implement this by augmenting equation (2) with a dummy variable for nonmetropolitan area as well as the interaction of this variable with $E L A$. Not surprisingly the strongest responses to ELA occurred in metropolitan areas. Consistent with changes in ELA increasing access to the Pill at age 18, use of the Pill in metropolitan areas with ELA was 30.4 percentage points higher-2.5 times the national mean in metro areas. This difference was 13.7 percentage points in less populated areas. Use of the Pill before age 21 was 26.9 percentage points, or 77 percent, higher among women with ELA in metro areas and 12.7 percentage points, or 31 percent higher, in nonmetro areas. These estimates

\footnotetext{
${ }^{13}$ An astute reader might puzzle over the divergence of the reported standard errors from what might be inferred using the reported mean dependent variable and $R^{2}$, especially the small standard error in column 1 . The difference in the standard error estimates across columns reflects both the role of the Huber-White correction for heteroskedasticity and for serial correlation (in year-of-birth cohort) within states. In column 1, the standard error increases to 0.042 when calculated under the (false) assumption of homoskedasticity (we are estimating linear probability models). Additionally correcting for serial correlation in birth cohort, the standard error becomes 0.017 , which is the standard error reported in column 1. In contrast, the correction for heteroskedasticity plays a less important role in columns 2-5, where corrections for serial correlation are more important.

${ }^{14}$ Although omitted here for brevity, we also find that these differences in use translated into meaningful differences in marriage timing (cf. Goldin and Katz 2002) and age at first birth (cf. Bailey 2006, 2009): women with ELA delayed marriage by an average of 0.42 years and motherhood by 0.25 years.
} 
are virtually unchanged with the inclusion of state linear time trends (see online Appendix C). For metro and nonmetro areas, the difference in Pill use for women with ELA fell to 10 percentage points and 3 percentage points, respectively, by age 22 , when early access laws ceased to bind. Stronger results in metropolitan areas are consistent with the difficulty of getting contraceptives anonymously in small towns or rural areas (even when legal). ${ }^{15}$

Although these results provide the best evidence in the literature of the relevance of ELA, we caution against using them as a denominator to approximate average treatment effects for Pill use on the treated (ATT) for several reasons. First, the retrospective nature of the sample and stigma about reporting premarital sex and contraceptive use would lead our analysis to understate the true effect of ELA on Pill use. ${ }^{16}$ Second, the 1970 NFS does not include unmarried young women. Because women with ELA tended to delay marriage (cf. Goldin and Katz 2002, Appendix C) and those who delayed the most (presumably by using the Pill more) are less likely to be sampled by the 1970 NFS, the effects of ELA on Pill use may also be understated. Understating the effects of ELA on Pill use for either reason would inflate ATT estimates. Third, the estimates for the subset of states that transition to ELA in the NFS may not represent the effects for the full set of cohorts (1943-1953) considered in the main analysis. Finally, even if the true effect of ELA on Pill use lies in our estimated range, dividing other ELA effects by this amount yields the ATT only if ELA has zero effect on women who did not use the Pill. That would not be the case if the option to use the Pill affects human capital investment or if there are general equilibrium effects in the marriage or labor market to the Pill's diffusion. For instance, as more women enter the workplace with ELA, women in these markets who did not use the Pill may benefit from reductions in employers' statistical discrimination. Whereas the NFS estimates of ELA on the use of oral contraception do not measure the Pill's effects on expectations or demand side responses in general equilibrium, the intention-to-treat estimates in the next sections measure its effects on outcomes through all of these channels.

\section{Results: How the Pill Affected Women's Lifecycle Wages}

\section{A. The Effect of the Pill on Women's Wages}

Figure 3 plots the effect of ELA on women's lifecycle wage earnings for four dependent variables in each of four panels. The figure includes our baseline specification using equation (1), a specification with abortion controls using equation $\left(1^{\prime}\right)$, and the four alternative specifications described above. Throughout the results section, our discussion focuses on the magnitudes of our estimates with abortion controls $\left(1^{\prime}\right)$, but it is important to note that the estimates from each of the other five specifications are generally not statistically different from those in $\left(1^{\prime}\right)$. (See online Appendix $\mathrm{C}$ for a tabular presentation of estimates for each of these five specifications.)

Across the six specifications and definitions of the dependent variable, Figure 3 shows a consistent pattern. Women with ELA earned less in terms of hourly and annual wages in their early twenties, but their wage and salary earnings grew more rapidly than their counterparts' as they aged. ${ }^{17}$ At ages 20 to 24, working women with ELA earned 3 percent less in hourly terms (Table 3, columns 1 and 2) and 9 percent less on an annual basis (Table 3 , columns 3 and 4). By their early forties, women with ELA earned a statistically significant premium of 5 percent hourly and 11 percent annually. This implies they earned

\footnotetext{
${ }^{15}$ Knowing the town doctor—or knowing that your parents did—or potentially being observed by your neighbor entering the local Planned Parenthood may have deterred many young women from seeking a prescription for the Pill, even if it was legal. Moreover, small town physicians may have been less willing to prescribe the Pill to unmarried women even when legal.

${ }^{16}$ See also Goldin and Katz $(2002$, 734, footnote 11), who note that the 1970 NFS question about retrospective pill use was only supposed to be asked for women who were married "a month before the date of the question." This provides an additional surveybased reason that Pill use would be underreported for unmarried women in the age range of interest.
} 
63 cents more per hour and roughly $\$ 2,200$ more per year. Notice that the annual amount is substantially larger than the $\$ 1,300$ implied by the hourly increase for a full-time, full-year worker, which is consistent with ELA also affecting labor-force participation. ${ }^{18}$ Column 5 confirms this. Including women who did not work increases the ELA annual wage premium to $\$ 2,700$ per year.

Although previous work links the diffusion of the Pill among younger, unmarried women to increased educational attainment (Hock 2008), women's lifecycle labor-force participation (Bailey 2006), and marital outcomes and occupational upgrading among college graduates (Goldin and Katz 2002), none of these studies explores the implications of these changes for women's wages, which is this paper's objective. The following sections extend the literature by reexamining these mechanisms and explicitly linking them to wages. For thoroughness, we replicate previous findings in the literature for a sample of all women and compare our findings, which are based on different cohorts and measures of ELA, to previous estimates. In addition, we add to the literature on the Pill's labor-market effects by examining novel outcomes such as on-the-job training and cumulative labor-market experience (Section IVB), and by considering how the Pill changed selection into human capital investments and paid work across ages (Section IVC).

\section{B. Mechanisms for the Pill's Effect on Wages}

Our earlier discussion provides three potentially reinforcing explanations for ELA's effects on wage profiles. The experience mechanism suggests that the initial increase in women's labor-force participation could have depressed wages at younger ages but increased wages later as these women accumulated labor-market experience and/or job/firm-specific capital. The on-the-job training mechanism requires no initial or longer run differences in laborforce participation, but suggests that workers with ELA increased their on-the-job human capital investments, which would also result in steeper wage earnings profiles. The formal human capital investment mechanism is consistent with women reducing their initial laborforce participation as they invested in their education or training and then reaping the returns to these early investments when they returned to the labor market, which would also result in steeper wage earnings profiles. Each of these explanations likely operated to some degree in practice, so our exploration of the Pill's labor-force participation effects here aims to shed light on the predominant mechanism for its observed wage effects. Importantly, each of these explanations postulates different labor-force participation and human capital investment patterns.

As a starting point, we examine the effect of ELA on women's labor market participation at the extensive ( $1=$ in the labor force) and intensive margins (using "usual weekly hours" for working women) and find that women with ELA participated less in their early twenties and more in their late twenties and thirties. ${ }^{19}$ These differences in labor-force participation resulted in different cumulative experience profiles as shown in panel A of Figure 4, and column 1 of Table 4, which define women's cumulative work experience as weeks worked multiplied by usual weekly hours summed across survey waves (see online Appendix A for more details). The results show that women with ELA had worked 18 percent fewer hours by their late twenties, but erased this deficit during their thirties. By their early forties,

\footnotetext{
${ }^{17}$ Although the estimates are not statistically different, it is noteworthy that using high school state rather than state at age 21 reduces the effect of ELA on wages. This is the case because we are less likely to have information on high school state for women who left the state for college. (Note that our estimates of college enrollment in Table 4 are also much smaller for this sample.) Because women attending out-of-state colleges may have been the most able or ambitious, it makes sense that our wage estimates are slightly smaller when we omit them.

${ }^{18}$ The annualized value of the hourly premium may also differ from the annual wages because the compensation information represents different pay periods. Hourly wages are from the most recent job, whereas annual wage and salary earnings reflect earnings in the previous calendar year, from 1968 to 1993, and in the previous 12 months after 1994.
} 
women with ELA had amassed the equivalent of 1.15 years more of full-time, full-year work (2,300 more hours) —an increase of over 10 percent relative to their same-aged peers without ELA, and about 30 percent larger than the increase found by O'Neill and Polachek (1993) between cohorts born in the mid-1930s and those born a decade later. ${ }^{20}$

This pattern of reduced labor-force participation is the reverse of the labor-supply shift needed to decrease wages at younger ages. Similarly, the on-the-job training channel is also inconsistent with early career dips in labor supply. If fewer women are working for pay, more cannot be accumulating on-the-job training at these ages. The Pill-induced accumulation of experience is most consistent with the formal human-capital investment channel, which postulates that ELA women used the Pill to make more investments in formal schooling and training early in their careers and enjoyed the returns on these investments in terms of steeper wage profiles, which also encouraged greater labor-force attachment, as they aged.

Panels B-F of Figure 4 examine ELA's effect on these more formal human capital investments including women's college enrollment, years of education, occupational training, and professional occupations for the six specifications. Table 4 presents estimates in tabular form. The results provide a rich picture of Pill-induced changes in women's career investments. College enrollment was 4.9 percentage points, or 20 percent, higher for women with ELA in their early twenties but not at later ages (Table 4, column 2; Figure 4, panel B). 21 Their advantage in grades completed (Table 4, column 3; Figure 4, panel C) peaks in their late twenties, at a little more than one-quarter of a year and erodes a bit as women without ELA returned to school in their thirties. A difference of one-quarter of a year of schooling, however, persists through the early forties. In addition to completing more formal education in their early twenties, women with ELA were 15 percent more likely to report occupational training (Table 4, column 4; Figure 4, panel D) in their late twenties. Although reports of occupational training remain modestly elevated for ELA women at older ages, the estimates are not statistically different from zero.

Women's greater human capital investments also appear in their occupational choices, which capture both observed (more formal education) as well as unobserved career investments (such as more career commitment or effort) (see online Appendix A for more information on occupational coding). With ELA, women were 17-30 percent (4-6 percentage points) more likely to be working in a professional or managerial job during their

\footnotetext{
${ }^{19}$ These findings are consistent with Bailey's (2006) results using repeated cross-sections from the March CPS, but the magnitudes in the NLS-YW are larger than in the CPS, but less precisely estimated owing to significantly smaller sample sizes. These differences in magnitude are expected because Bailey's (2006) use of current state of residence (rather than residence at age 21) should attenuate her results. For brevity, we omit estimates for labor-force participation from this paper and compare our NLS-YW estimates to Bailey (2006) in this footnote. At ages 25-34, women with ELA were roughly 3.8 percentage points, or 6 percent, more likely to work for pay in the NLS-YW. Bailey reports an almost identical estimate (3.9 percentage points for women ages 26-30), but her estimate is smaller at 1.6 percentage points for women ages 31 to 35 . The NLS-YW also shows a larger effect in the late thirties than the CPS, although the NLS-YW estimate is statistically insignificant. The effect of ELA on hours worked (excluding zeros) in the NLS-YW is not as comparable, because it asks usual hours worked whereas the CPS asks the number of hours worked in the CPS reference week. The effects at older ages are larger for usual hours worked in the NLS-YW, where women 30-34 years old worked one additional hour per week, on average, 2.5 percent more than their counterparts without ELA; 35-44 year-olds worked 1.3 to 1.7 additional hours, or 3.5 to 4.8 percent more. Full results are available upon request.

${ }^{20}$ The comparison with O'Neill and Polachek is approximate, both because they analyze slightly different groups of women and because their measure of labor market experience is different. In particular, they count years in which at least 26 weeks were worked as a full year of experience; changes at the extensive margin or changes on the intensive margin that do not cross the 26-week threshold are thus missed by their measure.

${ }^{21}$ Estimates are 30 percent larger than our baseline estimate ( 0.066 for a 27 percent increase) when we include controls for Vietnam mobilization. Estimates are 50 percent smaller ( 0.026 for an 11 percent increase) when we use high school state. Using high school state reduces our estimates because we are less likely to have information on high school state for women who went out of state to college. Thus, our sample of women for whom we have high school state disproportionately drops out-of-state college enrollees. These estimates are larger than reported in Hock's (2008) working paper. Using the October CPS, he finds-using a different measure of ELA - that college enrollment was roughly 2.5 percentage points higher among 21 and 22 year olds with ELA.
} 
late twenties and thirties, respectively (Table 4 column 5; Figure 4, panel E). Half of this increase in the late twenties, and all of it during the thirties, was due to entry into nontraditionally female professional occupations-professions other than nursing or teaching (Table 4, column 6; Figure 4, panel F). It is also interesting that differences in professional work erode with age, as female professionals with ELA retire. ${ }^{22}$

Together, more investments in formal human capital and greater labor-market attachment contributed to women's steeper age-earnings profiles. But given ELA's reduction in laborsupply during women's early twenties, the decrease in working women's wages at those ages remains an open question. It is also unclear to what extent changes in the composition of women investing in their human capital and working for pay drive the increase in women's wages at older ages. We address both questions in the next section.

\section{Heterogeneous Effects of the Pill and the Role of Workforce Composition in Wage Growth}

In addition to shifting women's investments in their human capital, early access to the Pill may have shifted which women pursued an education, went to graduate or professional school, and got promoted. If higher ability women disproportionately used the Pill to make career investments, and thus were initially more likely to be out of the labor force, then women working during their early twenties may have been negatively selected. As higher ability women entered the work force in their later twenties after having made their career investments, their greater skills (unobserved and observed) would lead their earnings profiles to be steeper than those of less skilled women. Moreover, less skilled women may have seen their earnings fall as their more skilled counterparts began working. In short, access to the Pill may have altered selection into the labor market at younger ages, which could help explain the effect of the Pill on age-earnings profiles shown in Figure 3.

To examine the importance of selection, we use a composite of respondents' performances on aptitude tests from their high school transcripts, which was reported to the NLS-YW in 1968 and called an "IQ score" in the documentation. IQ is available for only two-thirds of the sample, so we divide respondents into IQ tertiles (low, middle, and high) to maintain sample sizes large enough for disclosure. ${ }^{23}$ Equation $\left(1^{\prime}\right)$ is then estimated for each of the IQ tertiles separately. We also examine heterogeneous effects of ELA by educational attainment (any, versus no college) and, for education outcomes, family background (socioeconomic status tertiles of families when the respondent was 14). Whereas IQ tertile measured in high school is not affected by ELA directly (cf. Table 1), educational attainment is (Table 4). The latter breakdown should be viewed as a description to help us explore how different groups of women differentially benefited from early access to the Pill.

Table 5 begins this analysis by examining the effect of ELA on women's hourly wages by IQ tertile and college attainment. ${ }^{24}$ Whereas ELA reduces or has no significant effect on earnings for the lowest IQ tertile (column 1), it increases them in the middle and upper third of the IQ distribution (columns 2 and 3 ) for women aged 30 to 49. Almost all of the wage

\footnotetext{
${ }^{22}$ Our estimates are larger than those found in Goldin and Katz (2002, table 5), who use a sample of US born college graduate women ages 30-49, and find that the Pill increased the share in professional occupations, excluding teachers and nurses, by 0.4 percentage point ( 3 percent). One reason for the difference may be that their estimate includes women in their forties, where we find smaller effects.

${ }^{23}$ Griliches, Hall, and Hausman (1978) point out that these IQ composite scores are missing "almost at random" in the National Longitudinal Survey of Young Men, which is also the case in the NLS-YW. See online Appendix A for details on the composite

${ }^{24}$ We note that the results in Table 5 are from samples that included observations with zero earnings, unlike Table 3, which included only observations with positive earnings. This change was unfortunately necessary for disclosure reasons but does not affect the patterns we observe.
} 
gains accrued to women in the middle of the IQ distribution, where the effects are largest both absolutely and relatively. For this group, women with ELA enjoyed greater hourly wages throughout their twenties and the premium grew to a statistically significant 20 percent at ages 30-49.

It is worth noting that the estimates in this table are from a more flexible version of the regression model that allows the state, cohort, and age group fixed effects to vary by IQ group. The fact that ELA had an effect within the middle-IQ group suggests that the labor market gains described previously are not the sole result of shifts in the composition of the workforce. Furthermore, if the wage effects of ELA were driven by changing selection into the labor market by women with different ability levels, we would expect the overall wage effects from models without IQ controls to be substantially larger than those from the Table 5 models that stratify by IQ tertile. Instead, Table 3 and Table 5 imply similar average estimates (compare the ELA estimates averaged across the three IQ tertiles in Table 5 to the overall population estimates in Table 3 ). ${ }^{25}$

The fact that the wage effects are strongest for women attending some college suggests that one mechanism for these middle-IQ women was college enrollment. Although ELA conferred little if any wage premium for women without college (column 4), women with some college (column 5) experienced lower wages in their early twenties (perhaps as they worked at temporary jobs) but a 12 percent wage premium in their late thirties. ${ }^{26}$ The effects for the highest IQ group are considerably smaller and not statistically significant at any age below 44, which suggests these women may have already been taking advantage of their educational and career opportunities without ELA. In contrast to these positive effects, the lowest IQ women with ELA suffered a statistically significant wage reduction of roughly 15 percent in their early thirties. Although this negative effect is consistent with the Pill increasing crowding in jobs where lower IQ women were working or decreasing the relative skills of lower IQ women, the estimate is not robust to the inclusion of state linear time trends (online Appendix Table C5B). The lack of wage benefits for lower IQ women may be related to the limited returns to human capital investments in low-skilled jobs or the absence altogether of these women's investments in their human capital, which we examine next.

The next set of tables explores how the Pill affected human capital investments and paid work by IQ and childhood SES. The estimates in Table 6, which use highest grade completed as a dependent variable, are roughly consistent with the pattern of ELA's effects on wages. The effects of ELA on education are large and positive in the middle of the IQ distribution and negative for the lowest IQ group. (These negative effects may reflect higher IQ women crowding out lower IQ women in colleges.) Unlike the wage estimates, however, ELA's effects on education are also large and statistically significant for the highest IQ tertile. By age 40, ELA's effects for the middle- and upper IQ groups translate into a 0.4 to 0.5 year schooling advantage. The right side of the table shows that ELA's effects are largest for women from the lowest SES households (columns 4-6). Women with ELA from the most disadvantaged backgrounds attained roughly half of a year more education than their peers (column 4). This is a large effect, amounting to roughly one-third of the difference in grades completed between women in the low- and middle-SES groups. ${ }^{27}$ Although our data do not reveal whether these effects arise at the stage of high school completion, college

\footnotetext{
${ }^{25}$ There are two other reasons why the averages of the estimates in Table 5 might differ from those in Table 3: the smaller sample in Table 5 (excluding women with missing IQ information) and the different outcome variable (including women with zero earnings). We further confirmed that the averages of the ability-group specific ELA estimates are also similar to the overall estimates when the samples both include women with zero earnings: the former tend to be smaller at younger ages but larger for women in their forties.

${ }^{26}$ The estimated effects of ELA by college attainment in Tables 5 (for wages) and 7 (for experience) may be smaller than for affected woman if the marginal women who attended college (because of ELA) had higher IQs, on average, than the women with ELA who did not attend college, but lower IQs than women who attended college without ELA.
} 
admission, or class standing and persistence, it is clear that higher IQ women with access to the Pill - especially those from disadvantaged households - were more likely to continue their educations. Thus, ELA shifted women's educational attainment into more of a meritocracy.

Is the heterogeneity in the Pill's effects by IQ apparent for labor force attachment as well? Table 7 uses cumulative labor-force experience to examine this question. As with education, the effect of ELA on labor force experience is largest for women in the middle and upper thirds of the IQ distribution and those with some college. Middle-IQ women (column 2) with ELA had accumulated 3,500 additional hours of work experience by their early forties, a 16 percent increase over the mean. Women in the highest IQ group (column 3) with ELA accumulated 2,800 additional hours by their early forties, an 11.5 percent increase over the mean. Echoing the wage results, the effects of ELA on labor force experience are largest for women with some college (column 5). ${ }^{28}$

In summary, the data support that the Pill influenced which women invested in their careers and shifted into paid work. Given the lack of labor supply or schooling gains for low-IQ women, the Pill appears to have induced positive selection into higher education and into the labor market. This analysis also shows different responses to early access to the Pill across IQ tertiles. While lower IQ women with ELA did not gain ground in terms of education or experience, both middle- and higher IQ women raised their educational attainment and accumulated greater work experience. Women with some college became more likely to work for pay. Interestingly, the Pill's larger effects on work experience accrued to women in the middle of the IQ distribution, not only to the high achievers who have been the focus of other studies. Thus, our findings highlight the different ways in which women across the IQ distribution used the flexibility conferred by early access to the Pill to opt into paid work. ${ }^{29}$

\section{Decomposing Pill-Induced Wage Gains}

To quantify the contribution of each of these different human capital investments to the estimated Pill premium in wages, we decompose women's ELA-induced log hourly wage premium in their late forties into five components: formal education, on-the-job training, cumulative experience, occupational choice, and changes in marital status (that affect wages through the income of a spouse). We present results using the standard Blinder-Oaxaca decomposition at the mean (Blinder 1973; Oaxaca 1973) and the recentered influence function procedure (RIF) proposed in Firpo, Fortin, and Lemieux (2009), which generalizes

\footnotetext{
${ }^{27}$ The effect of ELA on college enrollment among 20-24 -year-olds for the lowest IQ group was 0.9 percentage points (standard error 3.6, mean 12 percent). It was 3.9 (standard error 3.5, mean 19 percent), and 5.9 percentage points (standard error 2.7, mean 37 percent) for the middle- and upper IQ groups, respectively. The effect of ELA on college enrollment among 20-24 -year-olds for the lowest SES group was 11.3 percentage points (standard error 3.8 percentage points), an implied increase of 108 percent (of the mean of 10.5 percent). It was 3.9 percentage points (standard error 4.1 , mean 21 percent) and 2.1 percentage points (standard error 3.0, mean 36 percent), respectively, for the middle- and upper SES groups.

${ }^{28}$ We also directly estimated the effect of ELA by IQ tertile and college attendance on labor force participation. The heterogeneity in effects is similar: women in the middle-IQ tertile in their late twenties and early thirties show the largest increases in participation. Higher IQ women also show increased participation at these ages, but the estimates are smaller and less precise. Women with some college show significant participation responses to ELA as well, with significantly lower rates in their early twenties, followed by significantly higher rates over the next decade.

${ }^{29}$ Another potential mechanism for the Pill's wage effects is its interaction with the marriage market and the size of spousal earnings. To investigate this "marriage-market channel," Appendix Table C4 in online Appendix C examines the relationship of ELA with both the likelihood of never having married (panel A) and the likelihood of having divorced (panel B) by IQ group and college attendance. In almost all cases, we cannot reject that the likelihood of having married is unrelated to ELA. In contrast, divorce rates were significantly higher for women with ELA in the lower IQ groups and among women without any college. Women in the lowest third of the IQ distribution with ELA were almost twice as likely to divorce (9.7 percentage points) by their late twenties (panel B, column 1). Similarly, ELA women with no college were almost 34 percent (4.4 percentage points) more likely to divorce. However, these effects are for the wrong groups of women to be driving the wage effects. Although they are strong for women in the middle of the IQ distribution, they appear for those without any college - not the middle-IQ women who pursued college. In short, little evidence points to divorce and the absence of a second earner as the explanation for the wage effects.
} 
Blinder-Oaxaca to other quantiles. This approach has the advantage of not being sensitive to the decomposition order and permits a richer characterization of the importance of Pillinduced changes in productive characteristics at different points in the skill distribution. To implement both procedures, we restrict the estimation sample to the last available wage observation for each woman in the 45-49 age group, and use women without ELA as the reference group.

Table 8 quantifies how much of the difference in the log hourly wage premium of women with ELA at various points along the wage distribution can be explained (in an accounting sense) by each of the characteristics. Panel A reports the Blinder-Oaxaca decompositions at the mean and shows that cumulative experience accounts for just under two-thirds of the Pill premium. Education and occupation each account for another sixth of the gap, with both job training and marriage having negligible effects. Together, these five factors explain over 90 percent of the ELA wage premium at the mean.

What do our estimates imply about the returns to education and experience for women? Women with ELA obtained 0.18 years more schooling by their late forties (Table 4, column 3 ), which increased their wages by $0.015 \log$-points (Table 8 , panel A), for an implied return of $0.083(=0.015 / 0.18)$. If we also attribute the entire $0.014 \log$-point increase in wages (Table 8, panel A) from occupational upgrading to schooling, the total return to women's schooling would be $0.161(=0.029 / 0.18)$. These estimates are both within a plausible range of Heckman, Lochner, and Todd's (2006) 0.128 estimate of the returns to education for white men in 1990 (Heckman, Lochner, and Todd 2006, 326). For the same group,

Heckman, Lochner, and Todd estimate coefficients on experience and experience squared of 0.1301 and -0.0023 , respectively (Ibid). Applying these returns to experience to our estimates indicates that, from an initial experience level of 15 years, 0.57 years more experience (Table 4, column 1) would increase women's log-wages by $0.034(0.1301 \times 0.57$ $\left.-0.0023 \times\left(15.57^{2}-15^{2}\right)\right)$. Our decomposition attributes more than that, $0.056 \log$ points, to the 0.57 years of additional experience, which is also reasonable if the returns to women's experience are higher than the returns for men or level off less quickly (cf. Weinberger and Kuhn 2010).

The results of the RIF procedure, shown in panel B, are consistent with the Oaxaca-Blinder decompositions, with experience accounting for the largest share of the premium, followed by education and occupation. ${ }^{30}$ The relative roles of experience and education-occupation, however, vary at different points in the wage distribution. Consistent with Table 5's result that the largest wage effects occur for women in the middle of the IQ distribution, panel B shows that the total log-wage differential associated with ELA varies non-monotonically across the distribution, and is largest (0.106) at the median. Furthermore, education and occupation explain relatively more of the wage gap (and cumulative experience relatively less) higher in the wage distribution. At the twenty-fifth percentile, the five components explain nearly all of the wage gap, while at the median, they explain about 85 percent of the gap. At the seventy-fifth percentile, they actually over-explain the gap, which suggests they may be offset by other factors near the top of the wage distribution.

\section{The “Opt-In" Revolution}

In 2003, Lisa Belkin's New York Times Magazine article, “The Opt-Out Revolution," reopened the debate about the reasons for persistent differences in women's and men's labor market outcomes. In particular, she argued that the women who might have been the

\footnotetext{
${ }^{30}$ The decomposition results are also similar if we use the semi-parametric approach of DiNardo, Fortin, and Lemieux (1996) to reweight the characteristics of women without ELA to resemble those of women with ELA at different points in the distribution.
} 
professional equals of men chose not to be-these women "opted out" to raise their children. Shang and Weinberg (2009) find some evidence that college graduate women have begun to have more children, but these changes seem small relative to the Opt-In Revolution that began 50 years ago.

This paper quantifies the role of the Pill in catalyzing this revolution. As the Pill provided women with cheaper and more effective control over childbearing in late adolescence, they invested more in their human capital and careers. Most affected were women in the middle of the IQ distribution and with some college, who experienced remarkable wage gains over their lifetimes. To put our results into perspective, the Pill-induced effects on wages amount to roughly one-third of the total wage gains for women in their forties born from the mid-1940s to early 1950s. ${ }^{31}$ Our decomposition shows that almost two-thirds of these Pillinduced gains (at the mean) can be attributed to increasing labor market experience and another third is due to greater educational attainment and occupational upgrading.

What do our estimates imply about the importance of the Pill in narrowing the gender gap from 1980 to 2000 ? To answer this, we simulate a counterfactual hourly wage distribution from the 1980,1990, and 2000 population censuses by removing age-specific estimates of early legal access to the Pill from the earnings of cohorts born after 1940 (Table 3, column 2) and compute the actual hourly wage distribution for men and women in 1980, 1990, and $2000 .{ }^{32}$ From 1980 to 1990 , the actual gender gap in real hourly wages for 25-49-year-olds closed by $0.126 \log$ points, and the simulated gender gap closed by $0.113 \log$ points. From 1990 to 2000 , the actual gender gap in real hourly wages closed by $0.074 \log$ points, and the simulated gender gap closed by $0.051 \mathrm{log}$ points. Our main estimates, therefore, imply that 10 percent of the narrowing in the gender gap during the 1980s and 31 percent during the 1990 s can be attributed to early access to the Pill. While improvements in contraception play an important role in increasing women's earnings, our results implicitly highlight the importance of other factors. The unexplained component of cross-cohort changes due to, for example, shifts in the demand for women's labor (e.g., anti-discrimination legislation and enforcement or changes in preferences) as well as shifts in the quality of women's education remain substantial.

Did the Pill unleash the Opt-In Revolution? Our results provide no conclusive answer. They may understate the Pill's broader influence because our empirical strategy does not allow us to explore the effect of changes in access to the Pill beyond age 20 and fails to capture the potentially large social multiplier effects. For instance, the Pill's availability likely altered norms and expectations about marriage and childbearing and firms' decisions to hire and promote women-even among cohorts without legal access to the Pill. Thus, the effects of the Pill may be larger than we find, but it is not clear how much larger. Even these conservative estimates, however, suggest that the Pill's power to transform childbearing from probabilistic to planned shifted women's career decisions and compensation for decades to come.

\footnotetext{
${ }^{31}$ This estimate is obtained by comparing the coefficients for $E L A \times 40-44$ and $E L A \times 45-49$ in Table 3 to the total change in wage rates for women in their 40s between the 1943-1946 and the 1951-1954 cohorts in the NLS-YW. Weinberger and Kuhn (2010) distinguish between changing "levels," the starting wage at labor force entry, and "slopes," the growth in wages after entry, and argue that changes in "slopes" can account for one-third of the narrowing in the gender gap over the last 40 years-a number they argue provides a reasonable upper bound for the importance of all post-schooling investments. Our measures of career investment combine both pre-market investments (e.g., college and occupational choice, which should shift levels) and post-market investments (e.g., labor market experience and on-the-job training, which should shift slopes).

${ }^{32}$ Real hourly wage is total wage and salary earnings of last year divided by the product of weeks worked last year and usual hours worked per week and divided by the PCE deflator to get year 2000 dollars. The estimates use IPUMS person weights and exclude real hourly wage outliers of less than $\$ 2$ or more than $\$ 200$. The sample contains native-born women ages $25-49$ whose wages were not imputed and who were not self-employed. The simulated log hourly earnings values are adjusted by subtracting the estimates in column 2 of Table 3 for women who were born in or after 1940 and born in a state where they would have had early access to the Pill.
} 


\section{Acknowledgments}

This research was supported by a core grant from the Eunice Kennedy Shriver National Institute of Child Health and Human Development (NICHD) to the Population Studies Center at the University of Michigan (R24 HD041028), which provided generous financial support for work in the University of Michigan Research Data Center (RDC). During work on this project, Hershbein was supported by the NICHD (T32 HD0007339) as a University of Michigan Population Studies Center (PSC) Trainee and by the PSC Marshall Weinberg Research Fellowship. The research in this paper was conducted while the authors were Special Sworn Status researchers of the US Census Bureau at the Michigan Census RDC. Research results and conclusions expressed are those of the authors and do not necessarily reflect the views of the Census Bureau. This paper has been screened to ensure that no confidential data are revealed. We are grateful to Jim Davis, Maggie Levenstein, Stan Sedo, and Clint Carter for extensive support with the preparation and revision of the restricted data proposal and disclosure process and to John Bound, Charlie Brown, John DiNardo, Claudia Goldin, David Lam, Thomas Lemieux, Bob Margo, Paul Rhode, Jeff Smith, Gary Solon, and Sarah Turner for helpful comments and suggestions.

\section{References}

Acemoglu, Daron; Autor, David H.; Lyle, David. Women, War, and Wages: The Effect of Female Labor Supply on the Wage Structure at Midcentury. Journal of Political Economy. 2004; 112(3): 497-551.

Ananat, Elizabeth Oltmans; Hungerman, Daniel M. The Power of the Pill for the Next Generation: Oral Contraception's Effects on Fertility, Abortion, and Maternal and Child Characteristics. Review of Economics and Statistics. 2012; 94(1):37-51. [PubMed: 22389533]

Bailey, Martha J. More Power to the Pill: The Impact of Contraceptive Freedom on Women's Life Cycle Labor Supply. Quarterly Journal of Economics. 2006; 121(1):289-320.

Bailey, Martha J. [accessed September 1, 2009] More Power to the Pill: Erratum and Addendum. 2009. Available at http://www-personal.umich.edu/ baileymj/Bailey_Erratum.pdf

Bailey, Martha J.; Hershbein, Brad; Miller, Amalia R. The Opt-In Revolution? Contraception and the Gender Gap in Wages: Dataset. American Economic Journal: Applied Economics. 2012. http:// dx.doi.org/10.1257/app.4.3.225

Belkin, Lisa. The Opt-Out Revolution. New York Times Magazine. 2003 Oct 26. http:// www.nytimes.com/2003/10/26/magazine/26WOMEN.html?pagewanted=all

Black, Sandra E.; Juhn, Chinhui. The Rise of Female Professionals: Are Women Responding to Skill Demand? American Economic Review. 2000; 90(2):450-55.

Black, Sandra E.; Spitz-Oener, Alexandra. Explaining Women's Success: Technological Change and the Skill Content of Women's Work. Review of Economics and Statistics. 2010; 92(1):187-94.

Blau, Francine D.; Kahn, Lawrence M. Swimming Upstream: Trends in the Gender Wage Differential in 1980s. Journal of Labor Economics. 1997; 15(1):1-42.

Blau, Francine D.; Kahn, Lawrence M. National Bureau of Economic Research (NBER) Working Paper 10853. 2004. The US Gender Pay Gap in the 1990s: Slowing Convergence.

Blau, Francine D.; Ferber, Marianne A.; Winkler, Anne E. The Economics of Women, Men, and Work. Upper Saddle River; Prentice Hall: 2010.

Blinder, Alan S. Wage Discrimination: Reduced Form and Structural Estimates. Journal of Human Resources. 1973; 8(4):436-55.

Bureau of Economic Analysis. National Income Product Accounts, Table 1.1.4: Personal Consumption Expenditures Price Index. 2009.

Bureau of Economic Analysis (BEA). Washington, DC: Aug. http://www.bea.gov/national/nipaweb/ SelectTable.asp?Selected $=Y$ [accessed August 17, 2009]

Chiappori, Pierre-Andre; Oreffice, Sonia. Birth Control and Female Empowerment: An Equilibrium Analysis. Journal of Political Economy. 2008; 116(1):113-40.

DiNardo, John; Fortin, Nicole M.; Lemieux, Thomas. Labor Market Institutions and the Distribution of Wages, 1973-1992: A Semiparametric Approach. Econometrica. 1996; 64(5):1001-44.

Duncan, Otis Dudley. A Socioeconomic Index for All Occupations. In: Reiss, Albert J., editor. Occupations and Social Status. Glencoe: Free Press of Glencoe; 1961. p. 109-38.

Fernandez, Raquel; Fogli, Alessandra. Culture: An Empirical Investigation of Beliefs, Work, and Fertility. American Economic Journal: Macroeconomics. 2009; 1(1):146-77. 
Fernandez, Raquel; Fogli, Alessandra; Olivetti, Claudia. Mothers and Sons: Preference Formation and Female Labor Force Dynamics. Quarterly Journal of Economics. 2004; 119(4):1249-99.

Firpo, Sergio; Fortin, Nicole M.; Lemieux, Thomas. Unconditional Quantile Regressions. Econometrica. 2009; 77(3):953-73.

Fortin, Nicole. [accessed September 1, 2009] Gender Role Attitudes and Women's Labor Market Participation: Opting-Out, AIDS, and the Persistent Appeal of Housewifery. 2009. http:// www.econ.ubc.ca/nfortin/Fortin_Gender.pdf

Ge, Suqin. Women's College Decisions: How Much Does Marriage Matter? Journal of Labor Economics. 2011; 29(4):773-818.

Goldin, Claudia. Understanding the Gender Gap: An Economic History of American Women. New York: Oxford University Press; 1990.

Goldin, Claudia. The Long Road to the Fast Track: Career and Family. Annals of the American Academy of Political and Social Science. 2004; 596(1):20-35.

Goldin, Claudia. The Quiet Revolution That Transformed Women's Employment, Education, and Family. American Economic Review. 2006; 96(2):1-21.

Goldin, Claudia; Katz, Lawrence F. The Power of the Pill: Oral Contraceptives and Women's Career and Marriage Decisions. Journal of Political Economy. 2002; 110(4):730-70.

Goldin, Claudia; Katz, Lawrence F. National Bureau of Economic Research (NBER) Working Paper 16281. 2010. Putting the 'Co' in Education: Timing, Reasons, and Consequences of College Coeducation from 1835 to the Present.

Goldin, Claudia; Katz, Lawrence F.; Kuziemko, Ilyana. The Homecoming of American College Women: The Reversal of the College Gender Gap. Journal of Economic Perspectives. 2006; 20(4): 133-56.

Griliches, Zvi; Hall, Bronwyn H.; Hausman, Jerry A. Missing Data and Self-Selection in Large Panels. Annales de l'inséé. 1978; 30/31(4-9):137-76.

Guldi, Melanie. Fertility Effects of Abortion and Birth Control Pill Access for Minors. Demography. 2008; 45(4):817-27. [PubMed: 19110899]

Heckman, James J.; Lochner, Lance J.; Todd, Petra. Earnings Functions, Rates of Return, and Treatment Effects: The Mincer Equation and Beyond. In: Hanushek, Eric A.; Welsh, Finis, editors. Handbook of the Economics of Education. Vol. 1. Amsterdam: Elsevier; 2006. p. 307-58.

Hock, Heinrich. [accessed December 1, 2008] The Pill and the College Attainment of American Women and Men. 2011. SSRN:http://ssrn.com/abstact=1023042 or http://dx.doi.org/10.2139/ssrn. 1023042

Joyce, Theodore; Tan, Ruoding; Zhang, Yuxiu. City University of New York (CUNY) Working paper. 2010. Changes in Birth Rates of Young Women Following Access to the Pill and Abortion in the Early 1970s.

Loughran, David S.; Zissimopoulos, Julie M. Why Wait? The Effect of Marriage and Child-bearing on the Wages of Men and Women. Journal of Human Resources. 2009; 44(2):326-49. [PubMed: 22993452]

Miller, Amalia R. The Effects of Motherhood Timing on Career Path. Journal of Population Economics. 2011; 24(3):1071-1100.

Mulligan, Casey B.; Rubinstein, Yona. Selection, Investment, and Women's Relative Wages over Time. Quarterly Journal of Economics. 2008; 123(3):1061-1110.

Oaxaca, Ronald. Male-Female Wage Differentials in Urban Labor Markets. International Economic Review. 1973; 14(3):693-709.

O'Neill, June; Polachek, Solomon. Why the Gender Gap in Wages Narrowed in the 1980s. Journal of Labor Economics. 1993; 11(1):205-28.

Paul, Eve; Pilpel, Harriet; Wechsler, Nancy. Pregnancy, Teenagers, and the Law, 1974. Family Planning Perspectives. 1974; 6(3):142-47. [PubMed: 4480441]

Paul, Eve; Pilpel, Harriet; Wechsler, Nancy. Pregnancy, Teenagers, and the Law, 1976. Family Planning Perspectives. 1976; 8(1):16-21. [PubMed: 1253949]

Shang, Qingyan; Weinberg, Bruce. Opting for Families: Recent Trends in the Fertility of Highly Educated Women. 2009. www.aeaweb.org/aea/conference/program/retrieve.php?pdfid=128 
Stevenson, Betsy; Wolfers, Justin. Marriage and Divorce: Changes and Their Driving Forces. Journal of Economic Perspectives. 2007; 21(2):27-52.

Weinberg, Bruce A. Computer Use and the Demand for Female Workers. Industrial and Labor Relations Review. 2000; 53(2):290-308.

Weinberger, Catherine J.; Kuhn, Peter J. Changing Levels or Changing Slopes? The Narrowing of the Gender Earnings Gap 1959-1999. Industrial and Labor Relations Review. 2010; 63(3):384-406.

Welch, Finis. Growth in Women's Relative Wages and in Inequality among Men: One Phenomenon or Two? American Economic Review. 2000; 90(2):444-49.

Wellington, Alison J. Changes in the Male/Female Wage Gap, 1976-85. Journal of Human Resources. 1993; 28(2):383-411. 


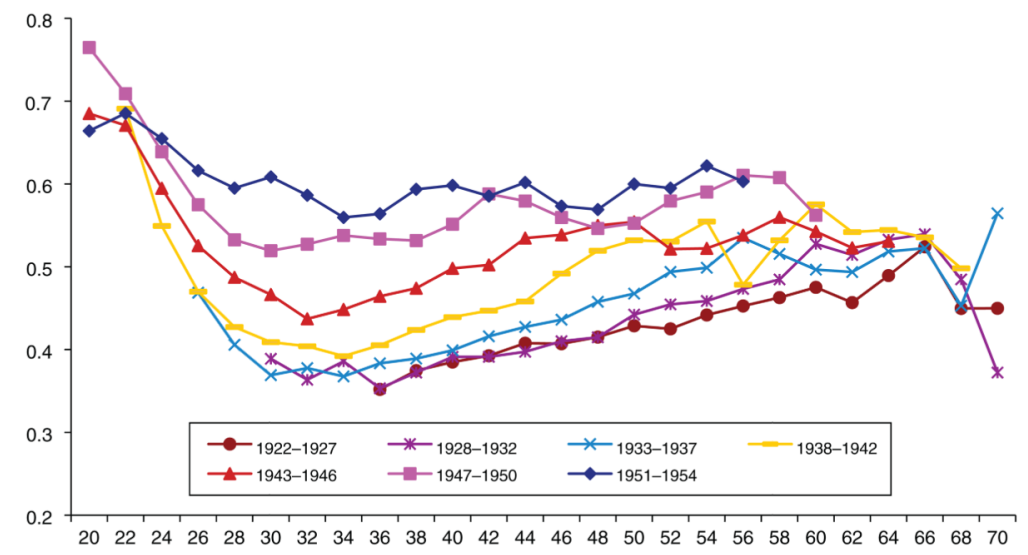

Figure 1. The Evolution of the Real Annual Wage Earnings of Women Relative to Men by Age and Birth Cohort

Notes: Annual labor earnings include income from all jobs, including self-employment. The series is adjusted for inflation to year 2000 dollars using the personal consumption expenditures deflator (BEA 2009). Data are weighted using CPS sample weights and collapsed into two-year age groups.

Source: 1964 -2009 March CPS 
Panel A. Share of women participating in the labor force relative to men

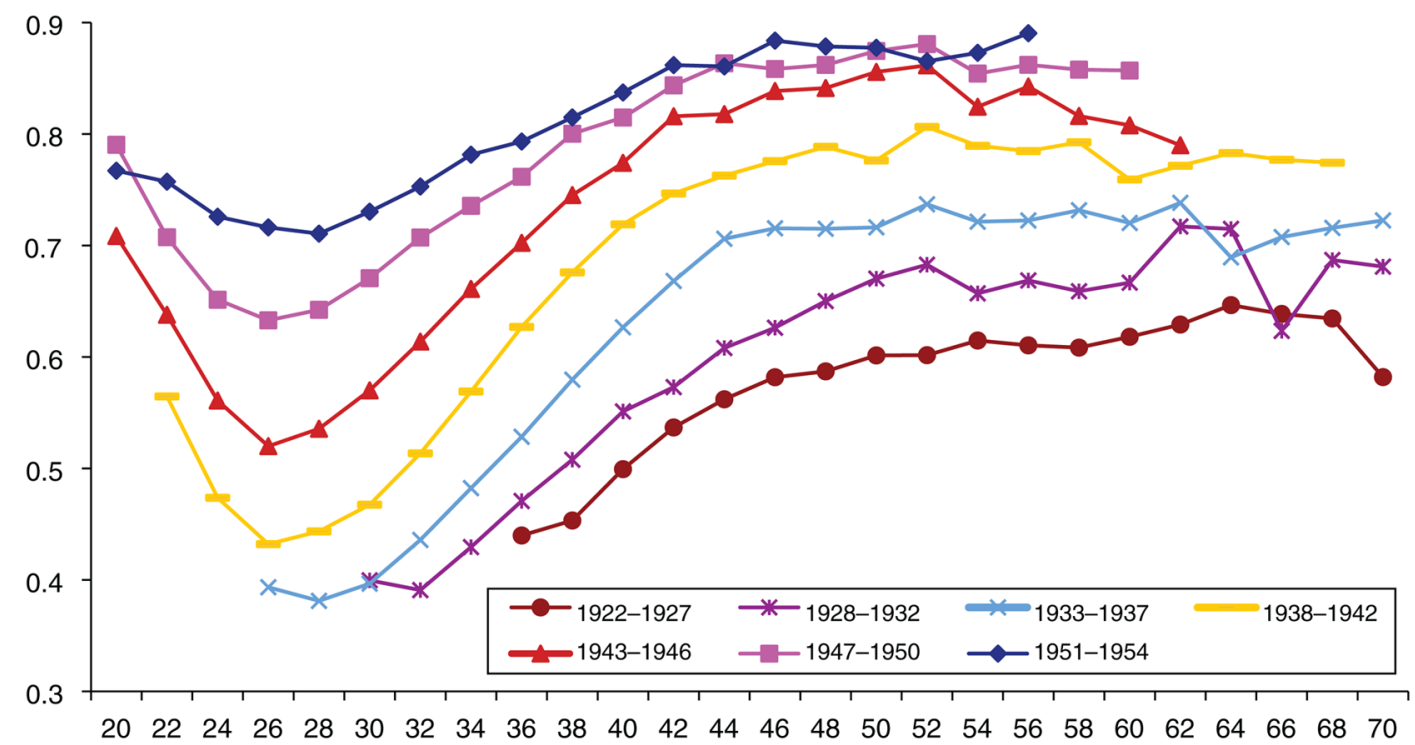

Panel B. Share of women working in professional and managerial jobs relative to men

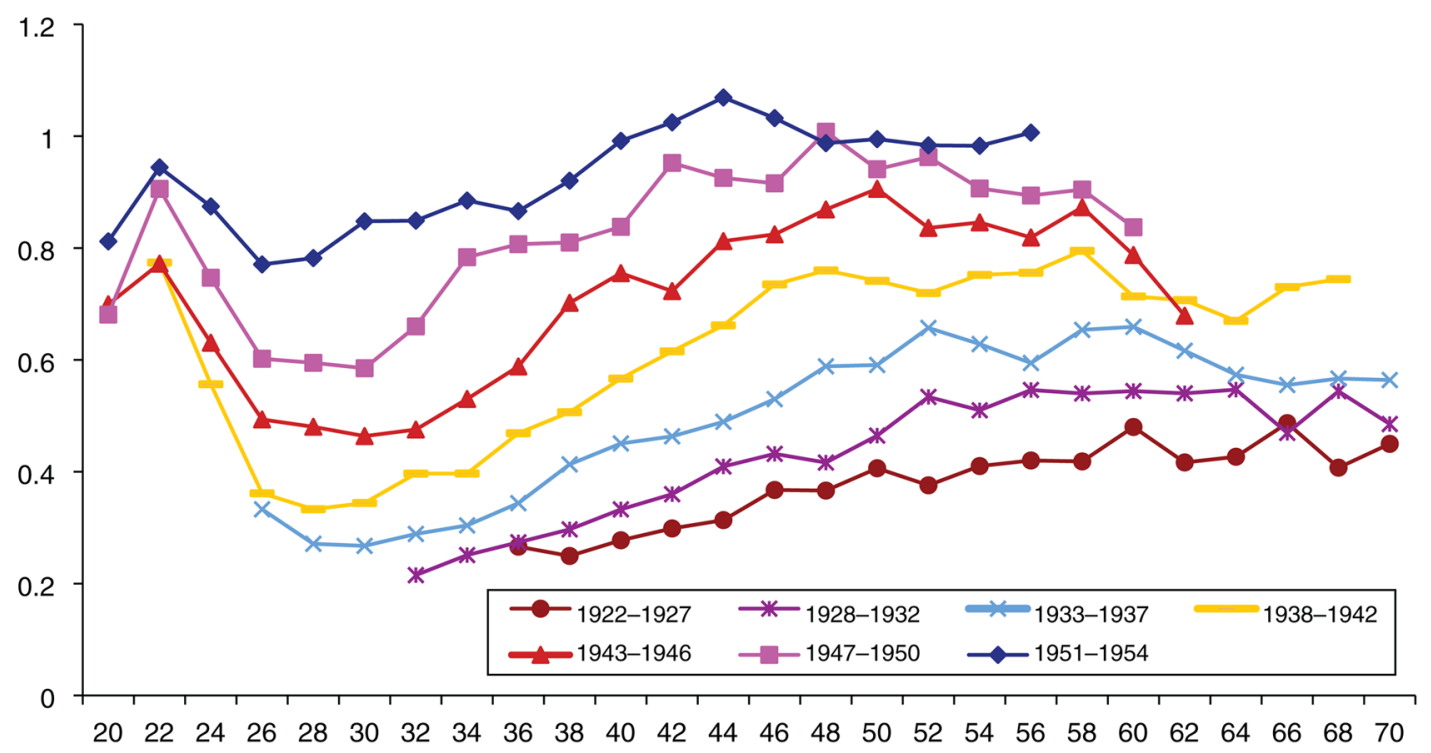

Figure 2. The Evolution of Human Capital Investments by Age and Birth Cohort

Notes: Share participating in the labor force is constructed from a binary variable indicating whether the respondent was employed or looking for a job at the time of the survey. Job groups are coded using the three-digit census occupational codes in the CPS. Women are counted in a job category only if they are employed at the time of the survey. Data are weighted using CPS sample weights and collapsed into two-year age groups.

Source: 1964 -2009 March CPS 
Panel A. Real hourly wages (excluding zeros)

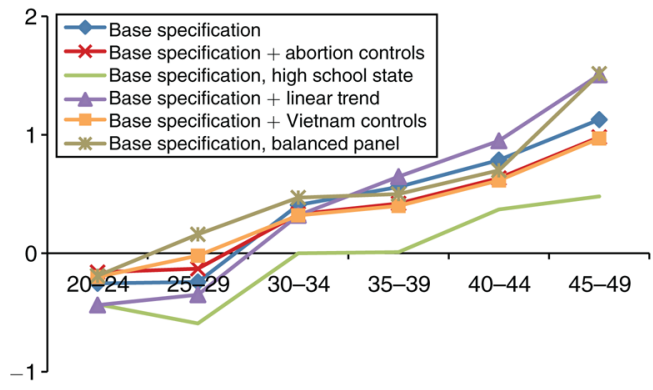

Panel C. Real wage earnings/salary last year (excluding zeroes)

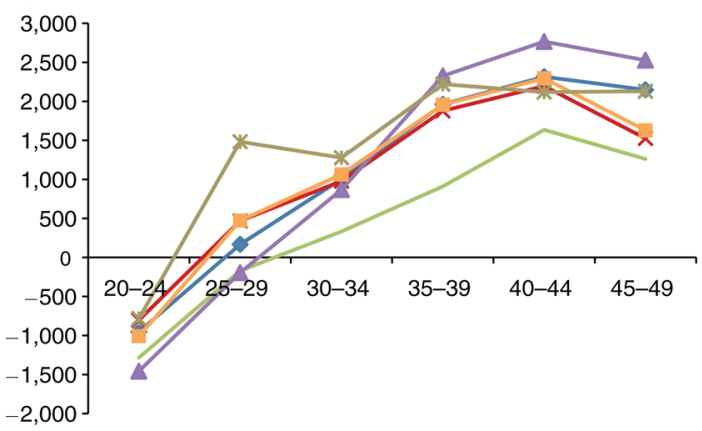

Panel B. Log hourly wages

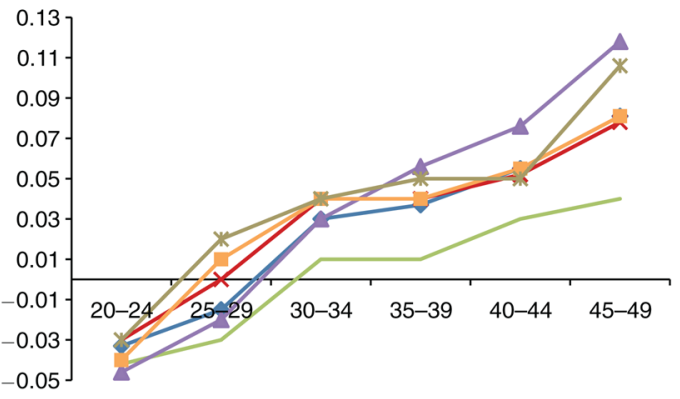

Panel D. Log wage earnings/salary last year

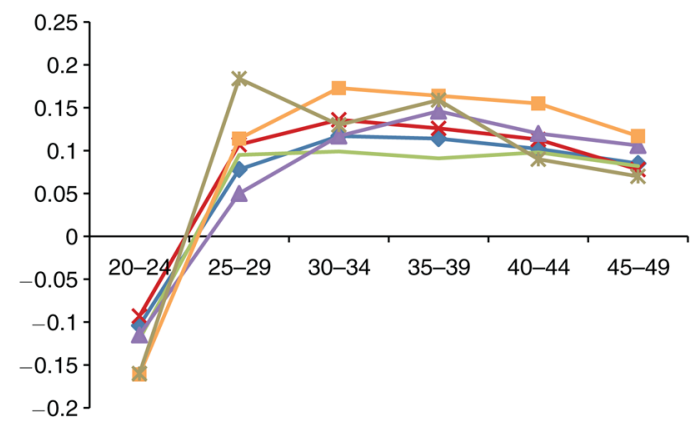

Figure 3. The Effects of Early Access to the Pill on Lifecycle Wage Earnings

Notes: Wage earnings are in 2000 dollars using the personal consumption expenditures deflator (BEA 2009). Each panel plots $\beta_{g}$ from six different regressions: baseline specification (equation 1); abortion controls (equation $1^{\prime}$ ), which corresponds to our tables; and four variants of equation $\left(1^{\prime}\right)$ : one with linear, state-specific time trends; another including controls for Vietnam casualties; another using only a balanced sample of respondents (those missing information in any year or attriting are omitted); and another using state where the respondent attended high school to match to $E L A$ (see footnote 21 regarding selection problems with this sample).

\section{Source: NLS-YW}



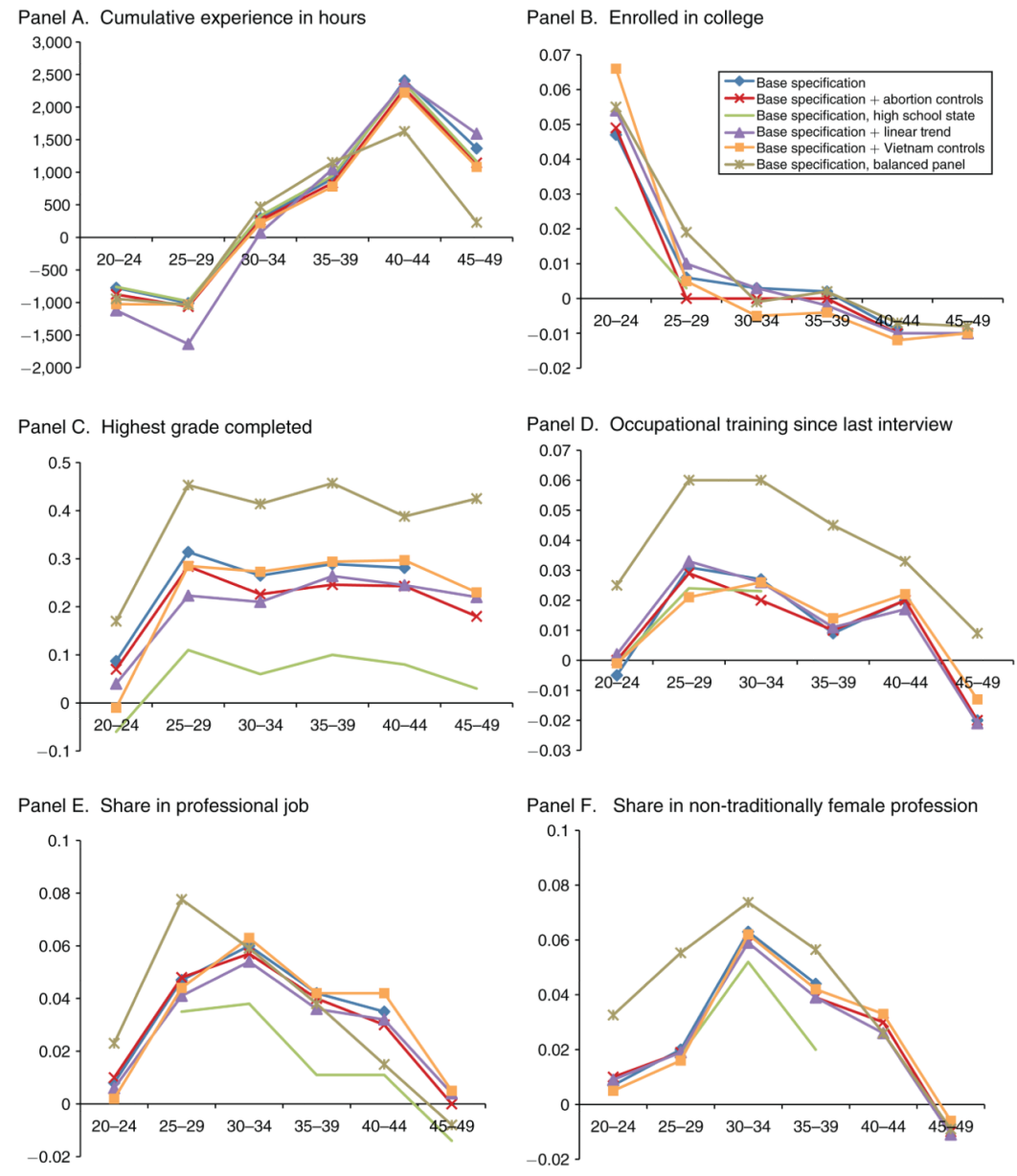

Figure 4. The Effects of Early Access to the Pill on Lifecycle Wage Earnings Notes: See notes to figure 3. 


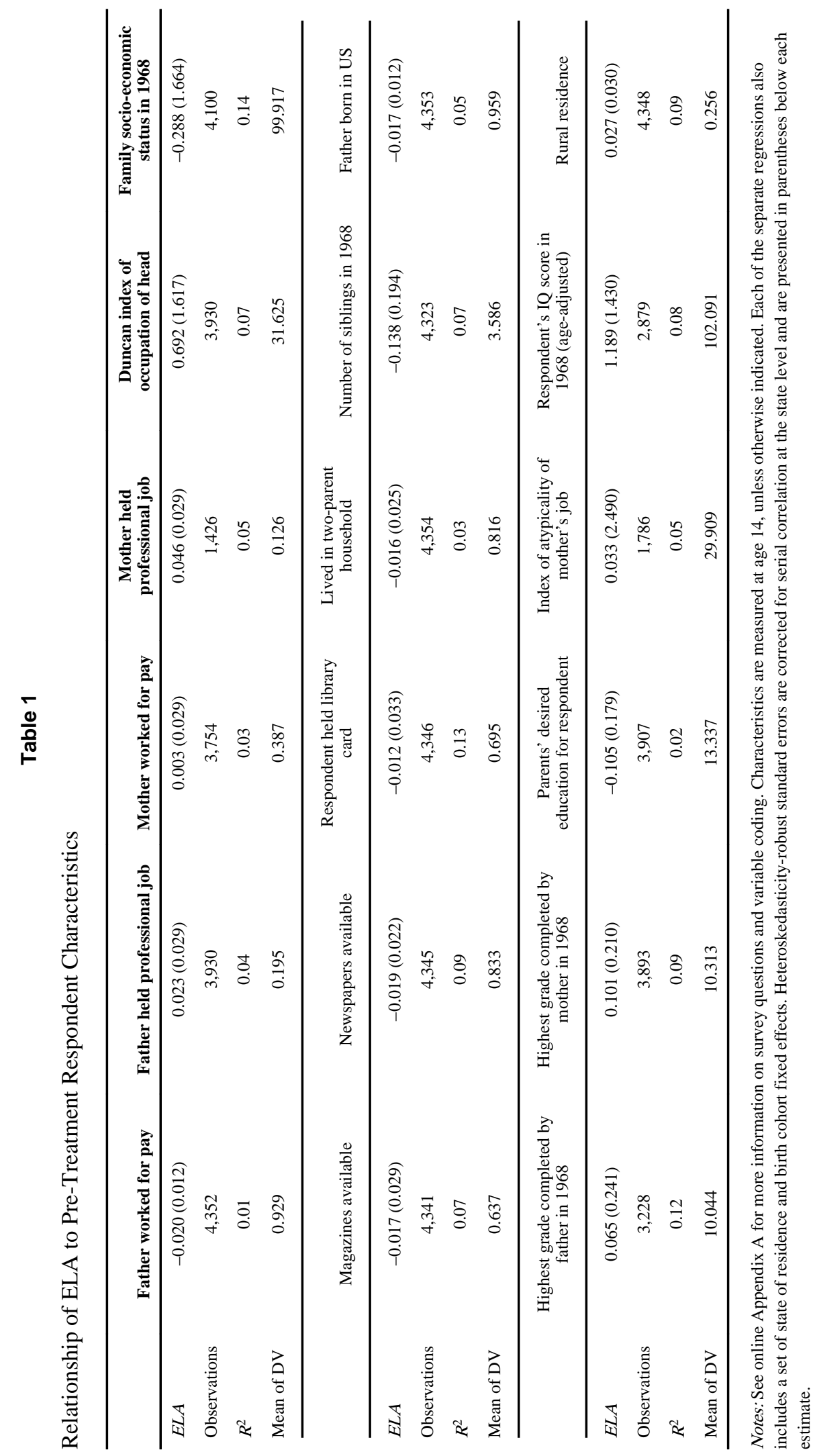




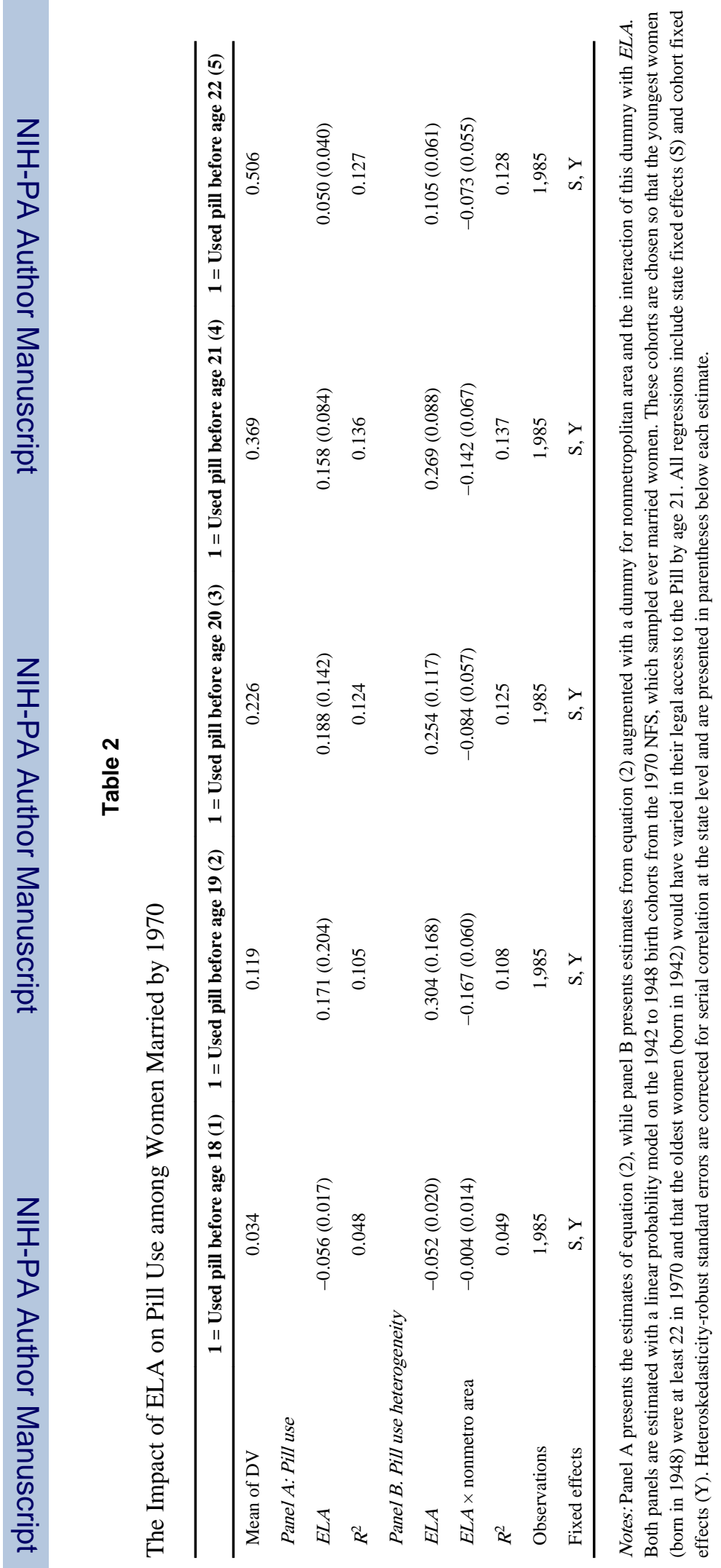




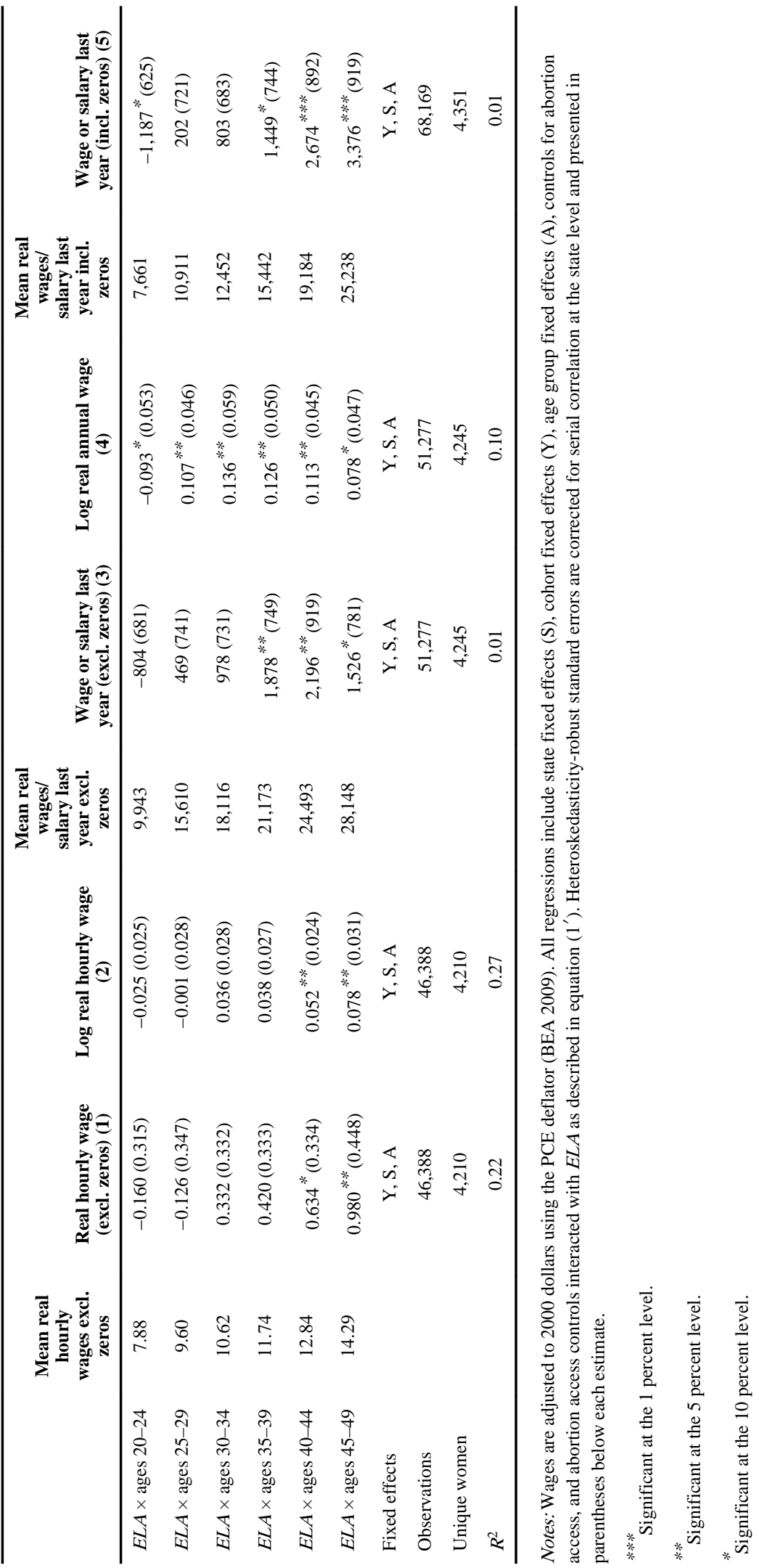




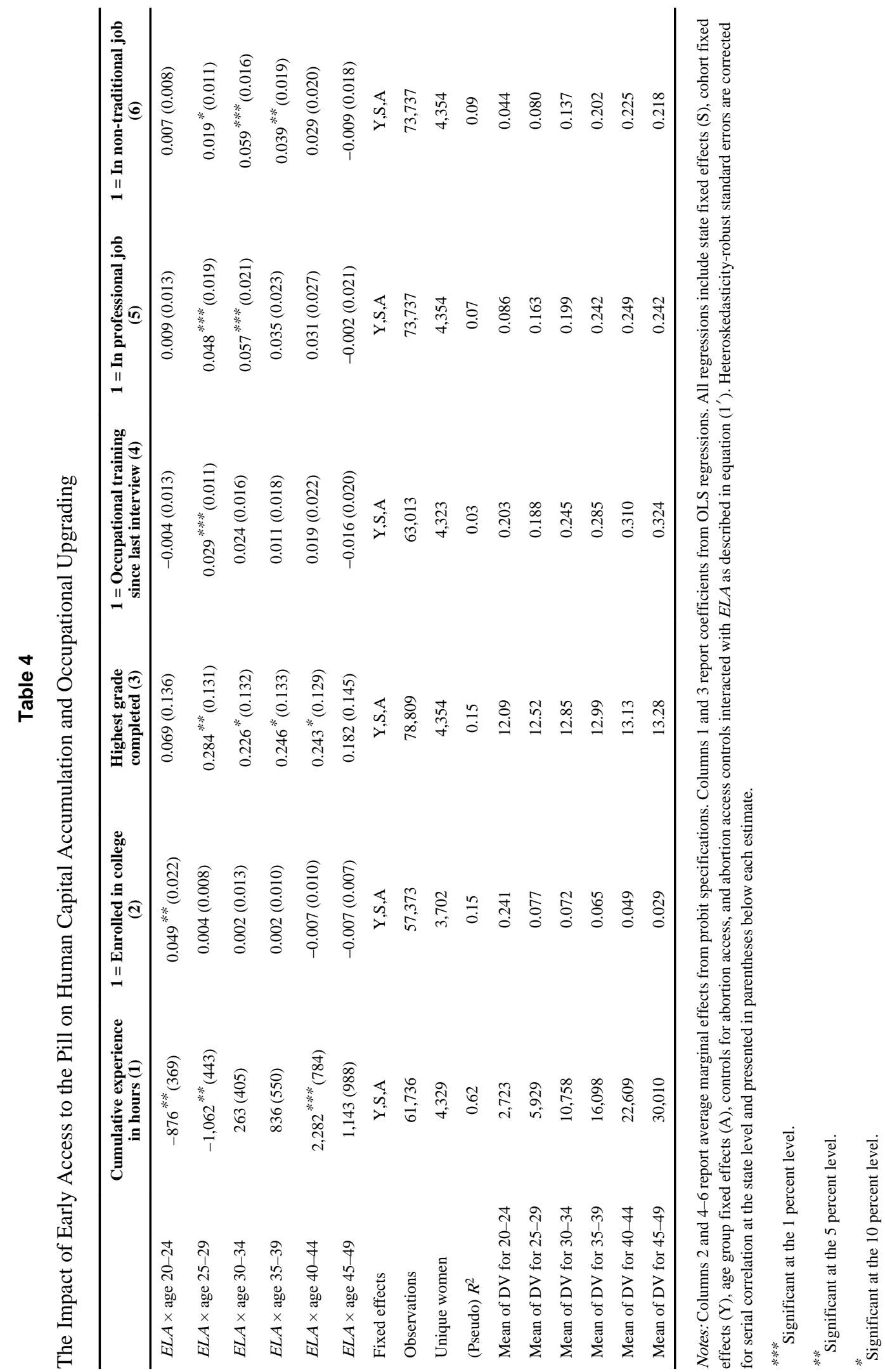




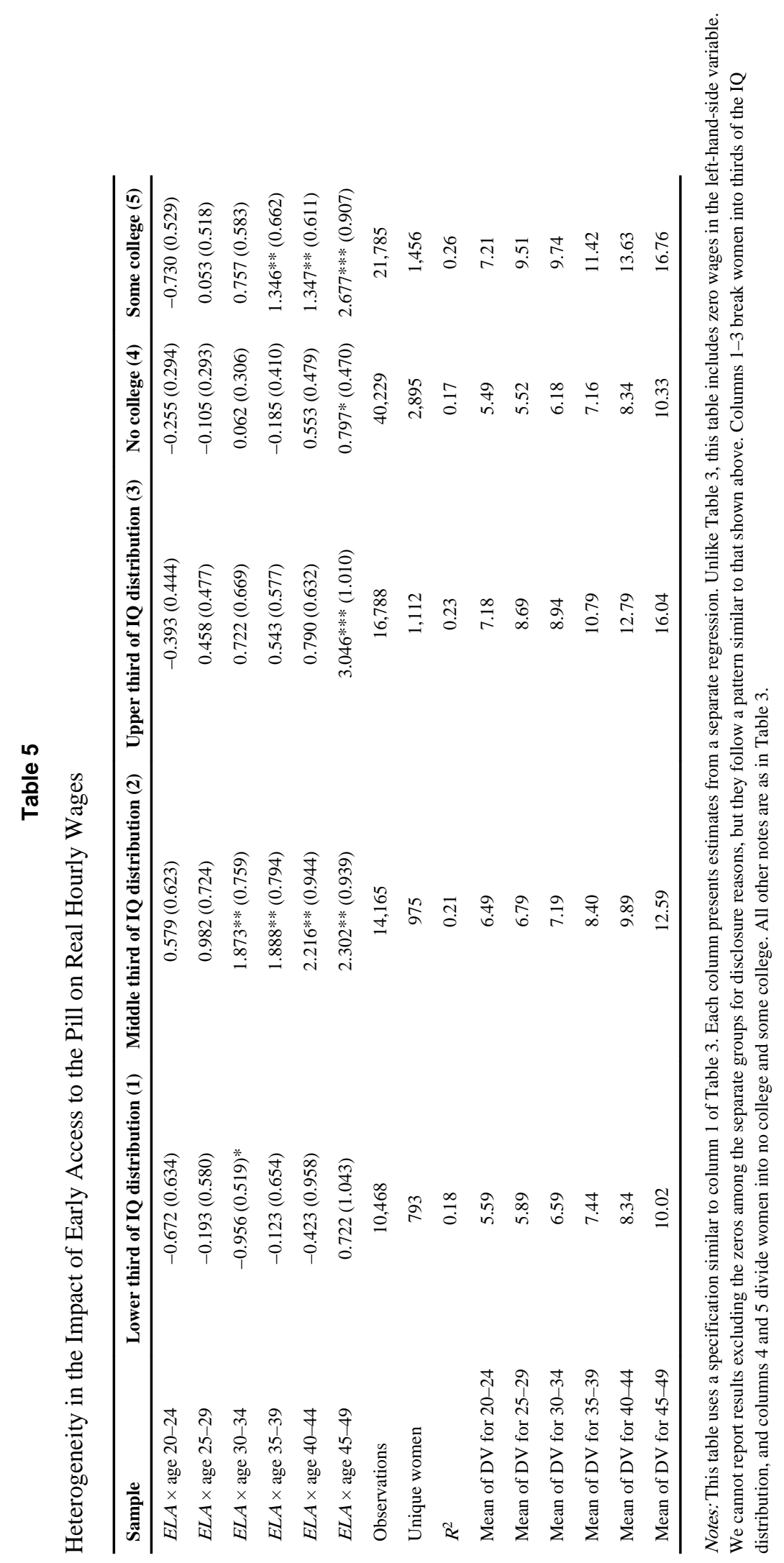




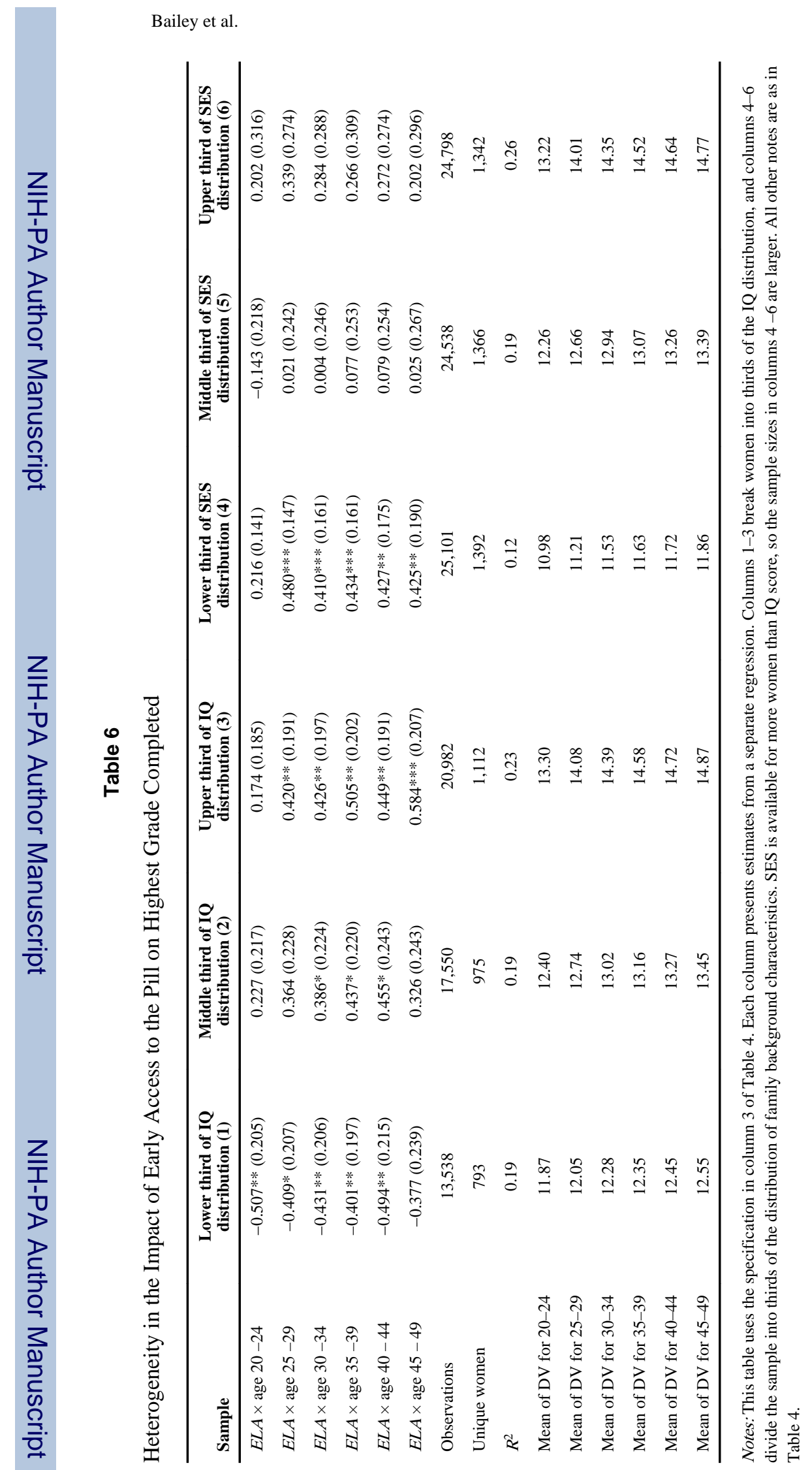

Am Econ J Appl Econ. Author manuscript; available in PMC 2013 June 17. 


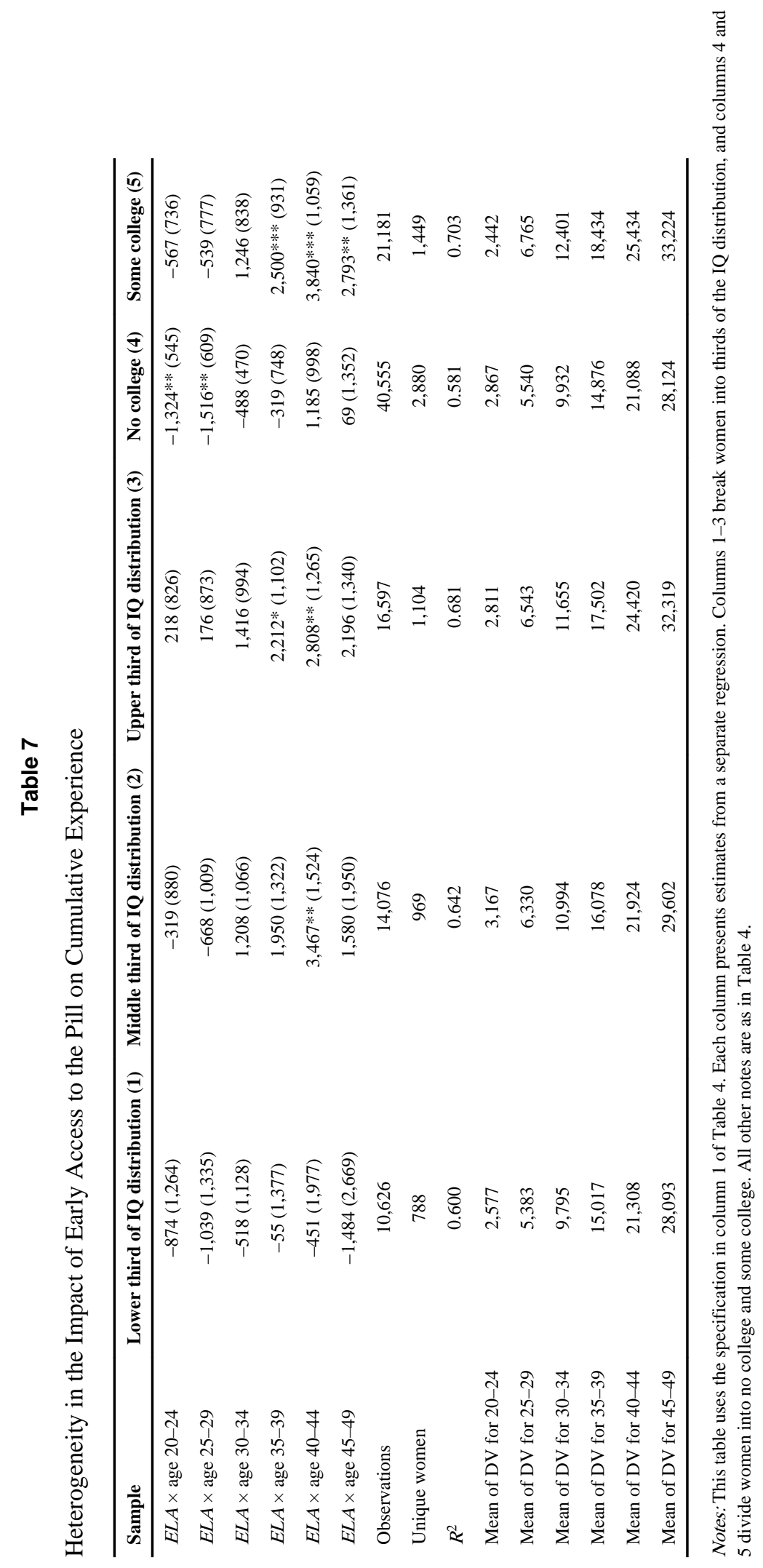




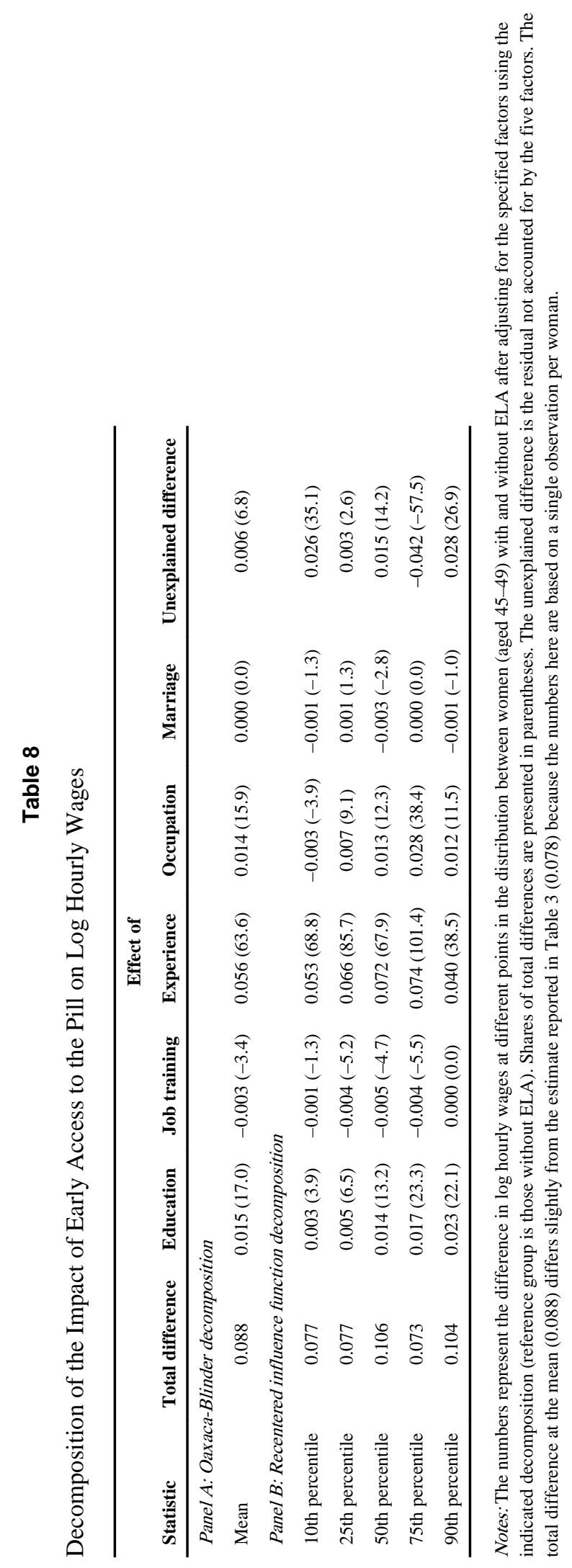

Am Econ J Appl Econ. Author manuscript; available in PMC 2013 June 17. 